2000s-54

\title{
Vertical R\&D Spillovers, Cooperation, Market Structure, and Innovation
}

Gamal Atallah

\begin{tabular}{c}
\hline Série Scientifique \\
Scientific Series
\end{tabular}

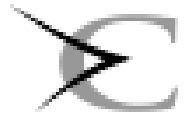

Montréal

Novembre 2000 


\section{CIRANO}

Le CIRANO est un organisme sans but lucratif constitué en vertu de la Loi des compagnies du Québec. Le financement de son infrastructure et de ses activités de recherche provient des cotisations de ses organisationsmembres, d'une subvention d'infrastructure du ministère de la Recherche, de la Science et de la Technologie, de même que des subventions et mandats obtenus par ses équipes de recherche.

CIRANO is a private non-profit organization incorporated under the Québec Companies Act. Its infrastructure and research activities are funded through fees paid by member organizations, an infrastructure grant from the Ministère de la Recherche, de la Science et de la Technologie, and grants and research mandates obtained by its research teams.

\section{Les organisations-partenaires / The Partner Organizations}

-École des Hautes Études Commerciales

-École Polytechnique

-Université Concordia

-Université de Montréal

-Université du Québec à Montréal

-Université Laval

-Université McGill

-MEQ

-MRST

-Alcan Aluminium Ltée

-AXA Canada

-Banque Nationale du Canada

-Banque Royale du Canada

-Bell Québec

-Bombardier

-Bourse de Montréal

-Développement des ressources humaines Canada (DRHC)

-Fédération des caisses populaires Desjardins de Montréal et de l'Ouest-du-Québec

-Hydro-Québec

-Imasco

-Industrie Canada

-Pratt \& Whitney Canada Inc.

-Raymond Chabot Grant Thornton

-Ville de Montréal

(c) 2000 Gamal Atallah. Tous droits réservés. All rights reserved.

Reproduction partielle permise avec citation du document source, incluant la notice (․

Short sections may be quoted without explicit permission, provided that full credit, including ( $)$ notice, is given to the source.

Ce document est publié dans l'intention de rendre accessibles les résultats préliminaires de la recherche effectuée au CIRANO, afin de susciter des échanges et des suggestions. Les idées et les opinions émises sont sous l'unique responsabilité des auteurs, et ne représentent pas nécessairement les positions du CIRANO ou de ses partenaires.

This paper presents preliminary research carried out at CIRANO and aims at encouraging discussion and comment. The observations and viewpoints expressed are the sole responsibility of the authors. They do not necessarily represent positions of CIRANO or its partners.

\section{ISSN 1198-8177}




\title{
Vertical Spillovers, Cooperation, Market Structure, and Innovation
}

\author{
Gamal Atallah ${ }^{\dagger}$
}

\section{Résumé / Abstract}

Cet article étudie les externalités de recherche verticales entre des firmes en amont et des firmes en aval. Il y a deux industries verticalement reliées, avec des externalités horizontales au sein de chaque industrie et des externalités verticales entre les deux industries. Quatre structures de coopération en R\&D sont considérées : pas de coopération, coopération horizontale, coopération verticale, et coopération horizontale et verticale simultanément. Les externalités verticales augmentent la $\mathrm{R} \& \mathrm{D}$ et le bien-être, alors que les externalités horizontales peuvent les augmenter ou les diminuer. La comparaison des structures de coopération en terme de R\&D révèle qu'aucune structure ne domine uniformément les autres. Le classement des structures de coopération dépend des externalités horizontales et verticales, et de la concurrence. Le classement dépend des signes et magnitudes de trois externalités concurrentielles (verticale, horizontale et diagonale) qui captent l'effet de la R\&D d'une firme sur les profits des autres firmes. Un des résultats de base de la littérature sur l'investissement stratégique est que la coopération entre concurrents augmente (diminue) la R\&D lorsque les externalités horizontales sont élevées (faibles); le modèle montre que ce résultat n'est pas toujours vérifié en présence des externalités verticales et/ou de la coopération verticale. Le papier propose une théorie reliant le degré d'innovation à la structure du marché : la relation entre la concurrence et l'innovation dépend des externalités horizontales, des externalités verticales et de la structure de coopération. Les incitations privées à la coopération en $R \& D$ sont examinées; on montre que les vendeurs et les acheteurs ont des préférences différentes quant au choix de structure de coopération et que les externalités augmentent la vraisemblance de l'émergence décentralisée de la coopération.

This paper studies vertical $R \& D$ spillovers between upstream and downstream firms. The model incorporates two vertically related industries, with horizontal spillovers within each industry and vertical spillovers between the two

\footnotetext{
* Corresponding Author: Gamal Atallah, CIRANO, 2020 University Street, 25 ${ }^{\text {th }}$ floor, Montréal, Qc, Canada H3A 2A5 Tel.: (514) 985-4000 Fax: (514) 985-4039 email: atallahg@ cirano.umontreal.ca This paper is based on the second chapter of my doctoral dissertation. I would like to thank Marcel Boyer, my thesis advisor, for insightful comments and suggestions. I would also like to thank Caroline Boivin, Leonard Dudley, Georg Erber, Ngo Van Long, Keith Newton, Michel Patry, Michel Poitevin, Jacques Robert, and Patrick Waelbroeck, as well as seminar participants at Industry Canada, Statistics Canada, the C.R.D.E. (Université de Montréal), the École des Hautes Études Commerciales, the $46^{\text {th }}$ International Atlantic Economic Conference, the $33^{\text {rd }}$ Annual Meeting of the Canadian Economics Association, the $40^{\text {ème }}$ Congrès de la Société canadienne de science économique, and the $17^{\text {ès }}$ Journées de Microéconomie Appliquée for useful comments.

${ }^{\dagger}$ Université de Montréal, C.R.D.E. and CIRANO
} 
industries. Four types of $R \& D$ cooperation are studied: no cooperation, horizontal cooperation, vertical cooperation, and simultaneous horizontal and vertical cooperation. Vertical spillovers always increase $R \& D$ and welfare, while horizontal spillovers may increase or decrease them. The comparison of cooperative settings in terms of $R \& D$ shows that no setting uniformly dominates the others. Which type of cooperation yields more $R \& D$ depends on horizontal and vertical spillovers, and market structure. The ranking of cooperative structures hinges on the signs and magnitudes of three competitive externalities (vertical, horizontal, and diagonal) which capture the effect of the $R \& D$ of a firm on the profits of other firms. One of the basic results of the strategic investment literature is that cooperation between competitors increases (decreases) $R \& D$ when horizontal spillovers are high (low); the model shows that this result does not necessarily hold when vertical spillovers and vertical cooperation are taken into account. The paper proposes a theory of innovation and market structure, showing that the relation between innovation and competition depends on horizontal spillovers, vertical spillovers, and cooperative settings. The private incentives for $R \& D$ cooperation are addressed. It is found that buyers and sellers have divergent interests regarding the choice of cooperative settings and that spillovers increase the likelihood of the emergence of cooperation in a decentralized equilibrium.

Mots Clés : Externalités de recherche verticales, structure de marché, innovation, coopération verticale en $R \& D$, politique de $R \& D$

Keywords: Vertical R\&D spillovers, market structure, innovation, vertical R\&D cooperation, $\mathrm{R} \& \mathrm{D}$ policy

JEL: L13, O32 


\section{Introduction}

Lately there has been an intensification of Research Joint Ventures and technological alliances between firms. For instance, Hagedoorn et al. (2000) note that the number of new technology partnerships set up annually went from 30-40 in the early 1970s to around 600 during the 1980s and 1990s. Appropriability is an important dimension of R\&D which has been the subject of a large theoretical and empirical literature. Although spillover analysis can be traced back to Ruff (1969), the modern theoretical treatment of the subject builds on the seminal papers by Spence (1984) and d'Aspremont and Jacquemin (1988).

Many variants of this basic model have been studied. ${ }^{2}$ Almost all of the studies in the strategic investment literature deal with horizontal spillovers between competing firms. Spillovers between buyers and sellers, which I call vertical spillovers, are one instance of interindustry spillovers. The main difference between horizontal and vertical spillovers is that the former are involuntary and (generally) undesirable from the point of view of the innovating firm, whereas the latter are desirable (and are more often voluntary). Another difference is that while horizontal R\&D cooperation may mitigate competition between firms, and is often closely monitored by competition authorities, vertical cooperation is less likely to hinder competition. Intraindustry cooperation is generally sufficient for firms to internalize horizontal spillovers. However, the internalization of vertical spillovers requires interindustry coordination. When vertical and horizontal spillovers are linked, a strong patent protection policy aiming at prohibiting competitors from acquiring the innovation may also harm vertically related firms (as well as firms in demand unrelated industries).

Whereas the empirical literature shows that vertical technological flows are significant, little theoretical treatment has focussed on this dimension of appropriability. Two exceptions are Peters (1995) and Harhoff (1991). Peters (1995) studies a model of vertical spillovers. He finds that more concentrated industries tend to spend more on $\mathrm{R} \& \mathrm{D}$ (however, this result may be reversed for high values of interindustry spillovers and some specific values of horizontal spillovers), horizontal spillovers may increase or decrease $R \& D$, and vertical spillovers increase $R \& D$ investments, profits, and welfare. The model suffers from some restrictive assumptions: spillovers are in one direction only, from suppliers to customers; upstream firms do not benefit from their own R\&D investments: all benefits accrue to downstream firms; upstream firms cannot adjust their output to their R\&D investments; finally, cooperation is not addressed. In a related paper Becker and Peters (1995) study R\&D competition between two vertical corporate networks in a patent race framework.

Harhoff (1991) studies a model of product R\&D spillovers between vertically related industries. He finds that upstream and downstream R\&D are generally substitutes: with an exogenous market structure and perfect vertical spillovers (in one direction only), only one of the two industries spends on

\footnotetext{
${ }^{2}$ Some of the issues examined are absorptive capacities (Cohen and Levinthal, 1990), price vs. quantity competition (Delbono and Denicolo, 1990), Stackelberg leadership (Goel, 1990), process vs. product innovation (Levin and Reiss, 1988), partial cartelization (Kamien and Zang, 1993; Poyago-Theotoky, 1995; De Bondt and Wu, 1997), asymmetric firms (Rosen, 1991; PoyagoTheotoky, 1996), asymmetric spillovers (Jarmin, 1993), and spillovers between demand unrelated industries (Steurs, 1994; 1995). Kamien et al. (1992) generalize this framework and study different combinations of cooperation and information sharing.
} 
imperfectly appropriable R\&D. ${ }^{3}$ However, his model suffers from some restrictive assumptions. The presence of a Stackelberg upstream monopolist makes the results applicable only to very asymmetric markets. Moreover, this market structure makes it impossible to study upstream horizontal spillovers along with downstream horizontal spillovers. Another restrictive assumption is that when (downstream) horizontal spillovers are allowed for, upstream prices are fixed exogenously. Moreover, vertical spillovers are perfect, and they accrue only from the seller to the buyers. Finally, cooperation is not addressed. $^{4}$

This paper studies vertical spillovers, allowing for different market structures, appropriability conditions, and types of cooperation. The model incorporates two vertically related industries, with horizontal spillovers within each industry and vertical spillovers between the two industries, in a threestage game theoretic framework. The contribution of the paper is threefold. First, this is the first paper to formalize vertical spillovers in a relatively general framework. Second, the study of cooperation goes further than existing studies by considering four different cooperative structures: no cooperation, interindustry and intraindustry cooperation, interindustry cooperation only, and intraindustry cooperation only. Finally, the paper addresses market structure explicitly, and provides a theory of innovation and market structure. The paper incorporates a large number of issues: horizontal spillovers, vertical spillovers, R\&D cooperation, market structure, endogenous cooperation. While this complicates the analysis and presentation of the results, I believe that omitting any of these variables would obscure some of the most important parts of the problem, such as the interplay between R\&D cooperation, spillovers, and market structure.

Here is a summary of the main findings of the paper. Vertical spillovers affect R\&D investments directly and indirectly, through their influence on the impact of horizontal spillovers and of $R \& D$ cooperation. Whereas horizontal spillovers may increase or decrease innovation and welfare depending on prevailing cooperation types, vertical spillovers always increase them. Cooperative settings are compared in terms of R\&D. It is shown that no type of cooperation uniformly dominates the others. The type of cooperation yielding more $R \& D$ depends on horizontal spillovers, vertical spillovers, and market structure. The ranking of cooperative structures hinges on the signs and magnitudes of three competitive externalities (vertical, horizontal, and diagonal) which capture the effect of the R\&D of a firm on the profits of other firms. The type of cooperation inducing firms to internalize a larger positive sum of competitive externalities yields more R\&D. In particular, one of the basic results of the strategic investment literature is that cooperation between competitors increases (decreases) R\&D when horizontal spillovers are high (low); the model shows that this result does not necessarily hold when vertical spillovers and vertical cooperation are taken into account. A theory of innovation and market structure is proposed: the effect of competition in one industry on total innovation depends on horizontal spillovers, vertical spillovers, cooperative settings, and competition in the other industry. The relation between competition and innovation can be understood in terms of the horizontal, vertical, and diagonal competitive externalities. Finally, the analysis of the private incentives for cooperation shows that buyers and sellers have different preferences over cooperative settings: sellers prefer vertical cooperation, whereas buyers (generally) prefer horizontal cooperation. Higher spillovers increase the likelihood of

\footnotetext{
${ }^{3}$ This is contrary to the results of Steurs (1994,1995), Peters (1995), and -as will be seen- our model, where it is found that there is a strong complementarity between interindustry research efforts.

${ }^{4}$ Vertical R\&D cooperation has been briefly addressed in the agricultural economics literature. See Freebairn et al. (1982) and Alston and Scobie (1983).
} 
cooperation, but the multiplicity of equilibria makes the decentralized choice of socially optimal cooperative settings uncertain.

The paper is organized as follows. Section 2 provides some background on vertical spillovers and vertical cooperation. The model is presented and solved in section 3. Comparative statics are studied in section 4. Section 5 compares R\&D expenditures between types of cooperation. In section 6 the relation between market structure and innovation is addressed. The private incentives for cooperation are studied in section 7. Section 8 concludes.

\section{Background}

There is ample evidence that interindustry spillovers -of which vertical spillovers are one instanceare significant. Bernstein (1988) and Jaffe (1986) find that interindustry spillovers have more effects on cost reduction than intraindustry spillovers. Bernstein finds that unit costs decrease more in response to an increase in intraindustry (interindustry) spillovers in industries with large (small) R\&D cost shares. Pavitt (1984) finds that out of 2,000 innovations in the UK, only 40\% emanated from the sector using the innovation.

Some evidence points more explicitly to vertical spillovers. ${ }^{5}$ Goto and Suzuki (1989) find that in the electronics industry, technological diffusion through spillovers is more important than technological diffusion through inputs. Ward and Dranove (1995) find important vertical spillovers within the American pharmaceutical industry. Suzuki (1993) and Branstetter (199?) find significant vertical spillovers in Japanese keiretsu. ${ }^{6}$ As Mohnen notes: "Interindustry knowledge spillovers are more likely to occur ... when one innovation naturally calls for the development of complementary products or innovations in an upstream input supply sector in order to reach its full potential." (Mohnen, 1989:5)

The role of vertically related firms in the development of new technologies is well documented. In the auto industry, much of the innovation comes from suppliers (Jorde and Teece, 1990). Clark et al. (1987) show the importance of the role played by die suppliers for new product development by Japanese automobile firms. Vanderwerf (1992) shows that upstream firms often create downstream innovations, even when the direct profit from the innovation accrues to downstream firms. This can be explained by the increase in final demand due to the innovation. Von Hippel (1988) finds that more than two thirds of first-to-market innovations concerning scientific instruments and process machinery in semiconductor and electronic subassembly manufacturing are dominated by end-users.

In some cases the complementarity between upstream and downstream innovation is sufficiently strong to require explicit vertical cooperation. "Vertical research joint ventures ... $(R J V s)$, which

\footnotetext{
${ }^{5}$ The ongoing trend toward more outsourcing increases the importance of the study of vertical spillovers. When firms had higher levels of vertical integration, a good part of vertical spillovers were internalized. However, with outsourcing, spillovers which were intra-firm become inter-firm/interindustry spillovers.

${ }^{6}$ Suzuki finds that spillovers from the core firm to its subcontractors are significant: a percentage increase in technology transfer reduces the unit variable cost of the subcontractor by $0.09 \%$. In the study of a sample of 208 Japanese manufacturing firms, Branstetter (199?) finds that production keiretsu promote innovative activity, as measured by firm-level spending on research and development. Moreover, he finds evidence that affiliation with production keiretsu groups promotes the exchange of technological knowledge across firms within groups.
} 
constitute a substantial fraction of $R J V s$, are designed to bring together complementary assets, usually research capacity and manufacturing or marketing" (Aghion and Tirole, 1993:7). Vertical technological cooperation is widely observed. It is sometimes argued that the high levels of vertical cooperation in the Japanese economy are responsible for much of Japan's competitive edge (Dyer and Ouchi, 1993). Sako (1995) argues that inter-supplier coordination (through kyoryokukai) in the Japanese automotive industry is also important. Moreover, suppliers with above (below) average technological capabilities prefer vertical (horizontal) technological cooperation. This is to be expected, since mutual learning between suppliers is more valuable when there is no fear of information leakage to competitors. Cassiman and Veugelers (1998), from the study of a sample of firms from the Belgian manufacturing industry, find that most cooperative agreements are vertical or with research institutes, rather than horizontal; they find that vertical cooperation is driven by the search for external knowledge and complementarities, rather than by sharing high costs or high risks of research. Veugelers (1993) finds that vertical relations account for $38 \%$ of Joint Ventures and for $25 \%$ of cooperative agreements. Since its foundation, SEMATECH (the Semiconductor Manufacturing Technology Consortium) has shifted from horizontal to vertical cooperation (Grindley et al., 1994).

Vertical cooperation has an important legal dimension. American antitrust laws are more restrictive regarding inter-firm technological cooperation than their European and Japanese counterparts (Jorde and Teece, 1990, 1992). For instance, European antitrust authorities grant cooperative R\&D agreements exemption from Article 85 of the Treaty of Rome governing broad aspects of competition among firms. The exemption applies for five years, regardless of market share, if the participants are vertically related and do not compete directly in the relevant market.

\section{The model}

The standard duopoly framework used in much of the strategic investment literature is quite restrictive. Here we use a more general market structure, for both upstream and downstream industries. This allows us to see how changes in market structure affect the relative desirability of different types of R\&D cooperation. Indeed, it will be shown that this comparison depends critically on market structure. Also, this allows us to analyze the effects of spillovers and cooperation on the relation between market structure and innovation. This yields results that are related to the literature studying the effect of the technological environment on the Schumpeterian hypothesis.

There are $m$ identical buyers of a standardized input, and $n$ identical suppliers providing this input. This market structure is given, so entry issues are put aside. If no R\&D is undertaken, suppliers incur a constant unit production cost of $s$ and sell the input at a unit price of $t$ to buyers. Buyers pay the suppliers $t$ for each unit bought, and incur an additional internal production cost of $r$. Finally, buyers sell the product to consumers at price $p .{ }^{7}$ Buyers face the linear inverse demand

$$
p=a-w \sum_{i=1}^{m} y_{b i}
$$

where $y_{b i}$ denotes buyer's $i$ output.

\footnotetext{
${ }^{7}$ The vertical chain contains only two industries for the sake of simplicity, but this assumption can also be justified by the empirical result that even though interindustry spillovers are important, each industry receives spillovers from a limited range of industries (Bernstein and Nadiri, 1988).
} 
Firms can engage in cost-reducing $\mathrm{R} \& \mathrm{D}$ activities. The dollar cost of $x$ units of R\&D for firm $i$ is $u x_{i}^{2}$, where $x_{i}$ represents the $\mathrm{R} \& \mathrm{D}$ output of firm $i$, and $u>0$ represents a cost parameter. It is assumed that $u$ is sufficiently high for the profit function to be concave, and sufficiently low for firms to choose strictly positive amounts of $R \& D$. Convex $R \& D$ costs can be justified by the observation of decreasing returns to scale in $\mathrm{R} \& \mathrm{D} .{ }^{8}$ With quadratic costs, many small research labs will be more cost effective than one big research unit. However, each firm is assumed to operate exactly one research lab, for the sake of simplicity. Total R\&D output will be denoted $X$.

Each unit of R\&D by a firm reduces its own cost by one dollar, reduces the cost of each of its competitors by $h$ dollars (horizontal spillovers), and reduces the cost of each firm in the other industry by $v$ dollars (vertical spillovers), ${ }^{9}{ }^{10}$ with $h, v \in[0,1] .{ }^{11}$ The spillovers $h$ and $v$ can differ for many factors: different absorptive capacities between suppliers/distributors and competitors, different levels of technological complementarities, differences in the efficiency of communication channels, and linkages between the degree of information leakage and the type of inter-firm interaction. The unit cost of production of a downstream firm is

$$
c_{b i}=t+r-x_{b i}-h \sum_{j \neq i}^{m} x_{b j}-v \sum_{i=1}^{n} x_{s i}
$$

The unit cost of production of an upstream firm is

$$
c_{s i}=s-x_{s i}-h \sum_{j \neq i}^{n} x_{s j}-v \sum_{i=1}^{m} x_{b i}
$$

Consequently, the final unit cost of a firm depends on its R\&D choice as well as on that of all other firms. Buyers benefit from sellers' R\&D through a reduction in the cost of their input, and through vertical spillovers. Sellers benefit from buyers' R\&D through the reduction in buyers' cost, and through vertical spillovers. Note that whereas R\&D expenses are independent of output, its benefits are linked to output, since the higher output is, the higher the number of units that benefit from cost reduction.

Parameters are assumed to be such that the following nonnegativity constraints are satisfied:

$$
\begin{aligned}
& r>x_{b i}+h \sum_{j \neq i}^{m} x_{b j}+v \sum_{i=1}^{n} x_{s i}, i=1, \ldots, m \\
& s>x_{s i}+h \sum_{j \neq i}^{n} x_{s j}+v \sum_{i=1}^{m} x_{b i}, i=1, \ldots, n .
\end{aligned}
$$

These constraints ensure that production costs after $R \& D$ is undertaken are strictly positive. The game

\footnotetext{
${ }^{8}$ See, for instance, Kamien and Schwartz, 1982. However, this issue remains controversial; see Nadiri, 1993.

${ }^{9}$ An important difference with Peters (1995) is that Peters assumes that vertical spillovers accrue only from suppliers to customers. However, there is no a priori reason why vertical spillovers should not be bi-directional. For instance, Suzuki (1993) finds vertical spillovers in both directions between core firms and their subcontractors in keiretsu.

${ }^{10}$ Spillovers from a firm need not be limited to its own buyers/suppliers. Suzuki (1993) identifies spillovers between the core firm in a keiretsu and the subcontractors belonging to other keiretsus. A percentage increase in technology transfer reduces the unit variable cost of the subcontractors by $0.11 \%$, an even larger spillover than between the firm and its own subcontractors. Those vertical spillovers (although in the second case one should speak of cross or diagonal spillovers) are found to be even more important than technological transfers between core firms from different keiretsus (horizontal spillovers), which are of the order of $0.08 \%$. Keiretsu provide an example where vertical spillovers are just as important empirically as, perhaps even more important than, horizontal spillovers.

${ }^{11}$ Imperfect spillovers can represent imperfect information leakage, the productivity of transferred knowledge (Peters, 1995), novelty requirements (Henriques, 1991), perfect information leakage with an absorption cost (for instance Levin et al. (1987) find that patents raise imitation costs and time), or perfect information leakage with differences in technology which cause only some of the information to be useful.
} 
has three stages: one R\&D stage and two output stages. In the first stage all firms decide on their R\&D simultaneously. In the second stage upstream firms compete in Cournot, taking into account the derived demand curve of the downstream industry. In the third stage there is a Cournot game among all downstream firms, taking the price of the intermediate good as given. The output stages follow the successive oligopoly structure suggested by Greenhut and Ohta (1979). The price of the intermediate good is determined by Cournot competition in the upstream industry, based on the derived demand curve of buyers. In horizontal models of R\&D investments, the output game is generally assumed to be simultaneous. Here, however, the vertical structure of the market implies that sellers are Stackelberg leaders. ${ }^{12}$

\subsection{Output stages}

We begin with the third stage where buyers decide non-cooperatively on their output, guaranteeing the perfectness of the equilibrium. Buyers's $i$ problem is

$$
\operatorname{Max}_{y_{b i}} \pi_{b i}=\left(p(Y)-c_{b i}\right) y_{b i}-u x_{b i}^{2}
$$

where $Y \equiv y_{b 1}+\ldots+y_{b m}$ Given that buyers are identical ex ante, they take the same decisions ex post. Simultaneous maximization of (1) for $i=1, \ldots, m$ and solving of the $m$ f.o.c. yields

$$
\begin{array}{r}
y_{b i}=\frac{a-t-r+(m-(m-1) h) x_{b i}-(1-2 h) \sum_{j \neq i}^{m} x_{b j}+v \sum_{i=1}^{n} x_{s i}}{w(m+1)} \\
p=\frac{a+m(t+r)-(1+(m-1) h) \sum_{i=1}^{m} x_{b i}-m v \sum_{i=1}^{n} x_{s i}}{m+1}
\end{array}
$$

From (2) we derive the inverse demand curve suppliers face

$$
t=\frac{m(a-r)+(1+(m-1) h) \sum_{i=1}^{m} x_{b i}+m v \sum_{i=1}^{n} x_{s i}-w(m+1) \sum_{i=1}^{n} y_{s i}}{m}
$$

We now turn to the second stage of the game, where suppliers decide non-cooperatively on their output, based on the derived inverse demand of downstream firms (3). Supplier $i$ solves the following problem:

$$
\operatorname{Max}_{y_{s i}} \pi_{s i}=\left(t(Y)-c_{s i}\right) y_{s i}-u x_{s i}^{2} .
$$

The identical costs of sellers imply that they will occupy identical positions ex post. Maximization and

\footnotetext{
${ }^{12}$ The use of a sequential model is one of the restrictive assumptions of the model. A simultaneous game for vertically related firms would avoid "the potentially restrictive assignment of leader-follower roles required by the Stackelberg solution." (Young, 1991:717). However, in a vertical market with prices as strategic variables, no equilibrium can be obtained in a simultaneous game; a simultaneous game would require the use of markups, not prices, as strategic variables (Young, 1991; Irmen, 1997). Other negotiation mechanisms could be used to obtain simultaneous output decisions between buyers and sellers. However, for the purpose of obtaining results which are comparable with other studies in this literature, and to maintain tractability, it is assumed that firms compete in output, implying sellers' leadership.
} 
simultaneous solving of the $n$ f.o.c. yields

$$
y_{s i}=\frac{m(a-r-s)+(1+(m-1) h+m v) \sum_{i=1}^{m} x_{b i}+m(n-(n-1) h+v) x_{s i}+m(-1+2 h+v) \sum_{j \neq i}^{n} x_{s j}}{w(m n+m+n+1)}
$$

Given that each unit bought from suppliers is transformed into one unit sold by buyers to consumers, total output is the same for upstream and downstream industries. Total output is

$$
Y=\frac{m n(a-r-s)+n(1+(m-1) h+m v) \sum_{i=1}^{m} x_{b i}+m(1+(n-1) h+n v) \sum_{i=1}^{n} x_{s i}}{w(m n+m+n+1)}
$$

and the final price is

$$
p=\frac{(m+n+1) a+m n(r+s)-n(1+(m-1) h+m v) \sum_{i=1}^{m} x_{b i}-m(1+(n-1) h+n v) \sum_{i=1}^{n} x_{s i}}{m n+m+n+1} .
$$

The price charged by suppliers is ${ }^{13}$

$$
t=\frac{m(a-r+n s)+(1+(m-1) h-m n v) \sum_{i=1}^{m} x_{b i}-m(1+(n-1) h-v) \sum_{i=1}^{n} x_{s i}}{m(n+1)} .
$$

\subsection{R\&D stage}

In the first stage of the game all firms decide simultaneously on R\&D levels. Whereas output is always chosen non-cooperatively, four types of cooperation $(T O C)$ will be considered for R\&D decisions: a non-cooperative equilibrium (NCE), a generalized cooperative equilibrium $(G C E)$, a horizontal cooperative equilibrium $(H C E)$, and a vertical cooperative equilibrium ( $V C E$ ). Figure 1 illustrates the different TOC. Note that in all four environments the source and destination (and also the level) of spillovers is independent of the TOC. That is, even when there are cooperating groups of firms, spillovers originate and end at individual firms. This is in contrast to empirical modelisation, where spillovers originate from industries.

[Figure 1 here]

Horizontal cooperation $(H C)$ represents cooperation with competitors, while vertical cooperation $(V C)$ represents cooperation with suppliers/distributors. Generalized cooperation $(G C)$ reflects the complexity of some research joint ventures: with the multiplication of research projects, firms may be adopting more than one structure simultaneously. Firms may engage in $H C$ on one project, and in $V C$ on another project. Many cooperative agreements involve both horizontal and vertical linkages. For instance, cooperation with a competitor may involve working with its suppliers.

Let $\beta \equiv\left\{x_{b 1}, \ldots, x_{b m}, x_{s l}, \ldots, x_{s n}\right\}$. Using the results of the second and third stages, we can write profit functions as functions of $\beta$. The profit of buyer $i$ is

$$
\pi_{b i}=\left(p(\beta)-c_{b i}(\beta)\right) y_{b i}(\beta)-u x_{b i}^{2} .
$$

The profit of seller $i$ is

$$
\pi_{s i}=\left(t(\beta)-c_{s i}(\beta)\right) y_{s i}(\beta)-u x_{s i}^{2}
$$

\footnotetext{
${ }^{13}$ Note that $t$ depends on the number of downstream firms; this is due to the presence of $R \& D$. In the absence of $R \& D$, with a linear demand (and also with a log-linear demand), $t$ is independent of $m$ (Choe, 1998).
} 
In the first $T O C$, the $N C E$, each firm chooses its R\&D so as to maximize its own profits, given that other firms do the same. The problem of buyer $i$ is

$$
\operatorname{Max}_{x_{b i}} \pi_{b i}
$$

and the problem of seller $i$ is

$$
\operatorname{Max}_{x_{s i}} \pi_{s i}
$$

Maximization and simultaneous solving of the $m+n$ f.o.c. of (4) and (5) yield research efforts in the $N C E$ by each buyer and each seller: ${ }^{14} 15$

$$
\begin{gathered}
x_{s i}^{N C}=\frac{m^{2}(1+m)(h+v+n-h n)(a-r-s)}{\gamma^{N C}} \\
x_{b i}^{N C}=\frac{n\left(1-h-m^{2}+h m^{2}-h m n-v m n-m^{2} n+h m^{2} n\right)(-a+r+s)}{\gamma^{N C}}
\end{gathered}
$$

where

$$
\begin{aligned}
\gamma^{N C}= & -h m^{2}+h^{2} m^{2}-v m^{2}+h v m^{2}-h m^{3}+h^{2} m^{3}-v m^{3}+h v m^{3}+n-2 h n+h^{2} n+h m n \\
& -h^{2} m n+v m n-h v m n-2 m^{2} n+4 h m^{2} n-3 h^{2} m^{2} n-2 h v m^{2} n-v^{2} m^{2} n-m^{3} n+h m^{3} n \\
& -h^{2} m^{3} n-v m^{3} n-h v m^{3} n-v^{2} m^{3} n-h m n^{2}+h^{2} m n^{2}-v m n^{2}+h v m n^{2}-m^{2} n^{2} \\
& +h m^{2} n^{2}-h^{2} m^{2} n^{2}-v m^{2} n^{2}-h v m^{2} n^{2}-v^{2} m^{2} n^{2}-2 h m^{3} n^{2}+2 h^{2} m^{3} n^{2}-2 v m^{3} n^{2} \\
& +2 h v m^{3} n^{2}+u w\left(m+2 m^{2}+m^{3}+2 m n+4 m^{2} n+2 m^{3} n+m n^{2}+2 m^{2} n^{2}+m^{3} n^{2}\right)
\end{aligned}
$$

In the $G C E$ each firm chooses its R\&D to maximize the total profits of all firms:

$$
\operatorname{Max}_{\beta} \quad \sum_{i=1}^{m} \pi_{b i}+\sum_{i=1}^{n} \pi_{s i}
$$

Maximization of (6) with respect to $x_{b i}, i=1, \ldots, m$ and $x_{s i}, i=1, \ldots, n$ yields research efforts in the $G C E$ :

$$
\begin{aligned}
& x_{b i}^{G C}=\frac{-(1-h+h m+v m) n(1+m+n)(a-r-s)}{\gamma^{G C}} \\
& x_{s i}^{G C}=\frac{m(1+m+n)(1-h+h n+v n)(-a+r+s)}{\gamma^{G C}}
\end{aligned}
$$

where

\footnotetext{
${ }^{14}$ The Salant and Shaffer (1998) critique of the use of symmetric R\&D strategies does not apply here, because there are no side payments and there is only one output market. Moreover, the very idea of side payments goes counter to the pre-competitive nature of R\&D collaboration.

${ }^{15}$ Under all TOC, R\&D expenditures depend on the sum $r+s$, not on the distribution of these two activities between upstream and downstream firms. Therefore, changes in the frontiers of firms have no effect on R\&D or welfare, subject to the fact that the constraint of nonnegativity of costs is nonbinding.
} 


$$
\begin{aligned}
\gamma^{G C}= & m-2 h m+h^{2} m+m^{2}-2 h m^{2}+h^{2} m^{2}+n-2 h n+h^{2} n+2 m n-2 h^{2} m n \\
& +4 v m n-4 h v m n+4 h m^{2} n-3 h^{2} m^{2} n+4 v m^{2} n-2 h v m^{2} n+v^{2} m^{2} n+h^{2} m^{3} n+2 h v m^{3} n \\
& +v^{2} m^{3} n+n^{2}-2 h n^{2}+h^{2} n^{2}+4 h m^{2}-3 h^{2} m n^{2}+4 v m n^{2}-2 h v m n^{2}+v^{2} m n^{2} \\
& +2 h^{2} m^{2} n^{2}+4 h v m^{2} n^{2}+2 v^{2} m^{2} n^{2}+h^{2} m n^{3}+2 h v m n^{3}+v^{2} m n^{3} \\
& -u w\left(1+2 m+m^{2}+2 n+4 m n+2 m^{2} n+n^{2}+2 m n^{2}+m^{2} n^{2}\right)
\end{aligned}
$$

In the $H C E$ there is intraindustry cooperation but no interindustry cooperation. Buyers solve

$$
\operatorname{Max}_{x_{b 1}, \ldots, x_{b m}} \sum_{i=1}^{m} \pi_{b i}
$$

and sellers solve

$$
\operatorname{Max}_{x_{s 1}, \ldots, x_{s n}} \sum_{i=1}^{n} \pi_{s i}
$$

Simultaneous solving of the $m+n$ f.o.c. of (7) and (8) yields research efforts in the $H C E$ :

$$
\begin{gathered}
x_{b i}^{H C}=\frac{(1-h+h m+v m) n^{2}(-a+r+s)}{\gamma^{H C}} \\
x_{s i}^{H C}=\frac{m(1+m)(1-h+h n+v n)(-a+r+s)}{\gamma^{H C}}
\end{gathered}
$$

where

$$
\begin{aligned}
\gamma^{H C}= & m-2 h m+h^{2} m+m^{2}-2 h m^{2}+h^{2} m^{2}+2 h m n-2 h^{2} m n+2 v m n-2 h v m n+2 h m^{2} n \\
& -2 h^{2} m^{2} n+2 v m^{2} n-2 h v m^{2} n+n^{2}-2 h n^{2}+h^{2} n^{2}+2 h m n^{2}-h^{2} m n^{2}+2 v m n^{2}+v^{2} m n^{2} \\
& +2 h^{2} m^{2} n^{2}+4 h v m^{2} n^{2}+2 v^{2} m^{2} n^{2}-u w\left(1+2 m+m^{2}+2 n+4 m n+2 m^{2} n+n^{2}+2 m n^{2}+m^{2} n^{2}\right)
\end{aligned}
$$

In the $V C E$ there is interindustry cooperation, but no intraindustry cooperation. Each buyer cooperates with one seller, but buyers do not cooperate among themselves, nor do sellers. Given that buyers are identical, as well as sellers, it is irrelevant which buyer cooperates with each seller. The VCE requires $m=n$ to exclude asymmetric strategies. Without loss of generality, let bi cooperate with si, $i=1, \ldots, m(m=n)$. Firms $b i$ and $s i$ maximize

$$
\operatorname{Max}_{x_{b i}, x_{s i}} \pi_{b i}+\pi_{s i}
$$

Following the maximization of (9) we find research efforts in the $V C E$ to be

$$
\begin{aligned}
& x_{b i}^{V C}=\frac{\left(n^{2}+v n^{2}+n^{3}+h n^{3}+2 v n^{3}+n^{4}-h n^{4}\right)(a-r-s)}{\gamma^{V C}} \\
& x_{s i}^{V C}=\frac{n\left(n+v n+n^{2}+h n^{2}+2 v n^{2}+n^{3}-h n^{3}\right)(a-r-s)}{\gamma^{V C}}
\end{aligned}
$$

where 


$$
\begin{aligned}
\gamma^{V C}= & -2 n^{2}+2 h n^{2}-2 v n^{2}+2 h v n^{2}-2 n^{3}-2 h n^{3}+2 h^{2} n^{3}-6 v n^{3}+2 h v n^{3}-2 v^{2} n^{3}-2 n^{4} \\
& +2 h n^{4}-4 h^{2} n^{4}-2 v n^{4}-6 h v n^{4}-4 v^{2} n^{4}-2 h n^{5}+2 h^{2} n^{5}-2 v n^{5}+2 h v n^{5} \\
& +u w\left(n+4 n^{2}+6 n^{3}+4 n^{4}+n^{5}\right)
\end{aligned}
$$

The following sections analyse the results derived above.

\section{Comparative statics}

The question addressed in this section is: what is the effect of changes in vertical and horizontal spillovers on R\&D and welfare, ${ }^{16}$ under different $T O C$ ? This analysis is performed in a bilateral duopoly framework. Proposition 1 summarises the effects of spillovers on R\&D and welfare.

Proposition 1. Let $m=n=2$. Then

i) Vertical spillovers always increase $R \& D$ by all firms, as well as welfare.

ii) Horizontal spillovers increase R\&D by all firms in the GCE and the HCE, and reduce R\&D by all firms in the NCE and the VCE.

iii) Horizontal spillovers increase welfare in all three cooperative equilibria (even when they reduce $R \& D)$, and have an ambiguous effect on welfare in the NCE.

iv) A simultaneous and equal increase in horizontal and vertical spillovers (starting from the same level) reduces $x_{b i}$ and increases $x_{s i}$ in the NCE (with an ambiguous effect on total $R \& D$ ), and increases $R \& D$ by all firms in all other TOC.

$v)$ In the NCE and the VCE, $v$ reinforces the negative effect of $h$, and $h$ mitigates the positive effect of $v$. In the GCE and the HCE, $h$ and $v$ reinforce the positive effects of each other.

Table 1 summarizes the comparative statics of the model. Comparative statics are obtained by substituting $m=n=2$ into the solutions for R\&D and performing the relevant differentiations. Figure 2 illustrates the effect of $h$ and $v$ on total R\&D. ${ }^{17}$

[Figure 2 here]

\footnotetext{
${ }^{16}$ Note that we focus on R\&D output, not effective (produced+received) R\&D. While the latter is more meaningful from a social point of view, $R \& D$ output is more amenable to empirical testing. Moreover, in this type of model there is generally a monotonic relationship between effective spillovers and welfare, therefore the welfare analysis implicitly addresses effective spillovers.

${ }^{17}$ This figure, and all other numerical simulations in the paper, are based on the following numerical parameterization of the model: $a=1000, w=1, r=s=50, u=600$.
} 
Table 1- Summary of comparative statics $(m=n=2)$

\begin{tabular}{|c|c|c|c|c|}
\hline & $\begin{array}{c}\text { No } \\
\text { cooperation }\end{array}$ & $\begin{array}{l}\text { Generalized } \\
\text { cooperation }\end{array}$ & $\begin{array}{l}\text { Horizontal } \\
\text { cooperation }\end{array}$ & $\begin{array}{c}\text { Vertical } \\
\text { cooperation }\end{array}$ \\
\hline$\partial x_{b i} / \partial v$ & + & + & + & + \\
\hline$\partial x_{s i} / \partial v$ & + & + & + & + \\
\hline$\partial W / \partial v$ & + & + & + & + \\
\hline$\partial x_{b i} / \partial h$ & - & + & + & - \\
\hline$\partial x_{s i} / \partial h$ & - & + & + & - \\
\hline$\partial W / \partial h$ & \pm & + & + & + \\
\hline$\partial x_{b i}(h=g) / \partial h$ & - & + & + & + \\
\hline$\partial x_{s i}(h=g) / \partial h$ & + & + & + & + \\
\hline$\partial X(h=g) / \partial h$ & \pm & + & + & + \\
\hline$\partial^{2} X / \partial h \partial v$ & - & + & + & - \\
\hline
\end{tabular}

An increase in $v$ increases $R \& D$ by all firms, in all equilibria. As $v$ increases, the flow of spillovers between the two industries increases, reducing the costs of all firms; this reduction in costs translates into an increase in output. This increase in output increases the value of cost reduction, inducing a further increase in R\&D. In contrast to $h$, vertical spillovers benefit all firms, and induce no disincentives for cost reduction. $^{18}$

In the $N C E$ and the $V C E$, an increase in $h$ reduces the private benefit from $\mathrm{R} \& \mathrm{D}$, thereby reducing R\&D by all firms. ${ }^{19}$ However, vertical cooperation reduces the negative effects of horizontal spillovers. Formally, in general we have that $\left|\partial X^{V C} / \partial h\right|<\left|\partial X^{N C} / \partial h\right|$ : horizontal spillovers reduce R\&D spending less under vertical cooperation than under no cooperation. With vertical cooperation, cost reduction is more highly valued, therefore leakages to competitors reduce $R \& D$ to a lesser degree than in the absence of cooperation. In the $G C E$ and the $H C E$, there is intraindustry cooperation, and, consequently, the positive externality is internalized: an increase in $h$ increases R\&D by all firms.

Note the asymmetric effects of spillovers on $\mathrm{R} \& \mathrm{D}$ : $\partial X / \partial h<0$ when there is no intraindustry cooperation $(N C$ or $V C)$, whereas $\partial X / \partial v>0$ even without interindustry cooperation $(N C$ or $H C)$.

\footnotetext{
${ }^{18}$ Vertical spillovers can have a (negligible) negative effect on a firm. When $v$ increases, the flow of spillovers to the firm from its suppliers/distributors increases, but the same also applies to competitors. When firms are identical, the positive effect of the reduction in own cost dominates the marginal negative effect of the reduction in competitors' (and the competitors' suppliers) costs. In a situation with strong asymmetries between firms, it could be the case that small firms lose from $v$, because most of the benefits go to their competitors, deteriorating further their initial cost disadvantage. Moreover, when a large firm has many suppliers, suppliers may worry about information leakage to the buyer, since this information may go to the supplier's competitors. Such a concern has arisen within SEMATECH (the Semiconductor Manufacturing Technology Consortium), where Semiconductor materials and equipment suppliers sharing information with SEMATECH members feared of information leakage to their competitors (Grindley et al., 1994).

${ }^{19}$ In the case of the derivatives $\partial x_{b}^{I C} / \partial h$ and $\partial x_{s i}^{I C} / \partial h$, it could not be formally proved that they are always negative, however numerical simulations show that whenever any of them is positive at least one of the nonnegativity constraints on costs is violated.
} 
Consider next the effect of a simultaneous and equal increase in vertical and horizontal spillovers $(d h=d v)$. Here $h$ and $v$ increase equally and simultaneously, assuming they are initially at the same level. This result is useful in a context where (desirable) leakage of information to suppliers implies the (undesirable) leakage of the same information to competitors. That effect is obtained by setting $h=v$ and differentiating with respect to the spillover level. As table 1 shows, in the three cooperative equilibria all firms increase their R\&D. In the $N C E$, buyers decrease, and sellers increase, their R\&D. Remember that, in the $N C E$, an increase in (only) $v$ increased R\&D by all firms whereas an increase in (only) $h$ decreased R\&D by all firms. This means that, when both types of spillovers increase simultaneously, the positive effect of $v$ dominates for sellers, while the negative effect of $h$ dominates for buyers. The effect on total $R \& D$ is ambiguous, depending on which dominates between the increase in $R \& D$ by sellers and the decrease in $R \& D$ by buyers. ${ }^{20}$

However, further analysis shows that the effect of a simultaneous increase in $h$ and $v$ in the $N C E$ and the $V C E$ tends to become negative as competition intensifies, due to the negative effect of non internalized $h$ on R\&D. Therefore, when the diffusion of technological information to vertically related firms makes this information available to competitors, and this (horizontal) externality is not internalized, it is preferable to limit the diffusion of information.

There is an -asymmetric- interaction between the effects of $h$ and $v$. In the $N C E$ and the $V C E$, $\partial^{2} X / \partial h \partial v<0$, meaning that $v$ reinforces the negative effect of $h$, and that $h$ mitigates the positive effect of $v^{21}$ In this case not only does $h$ reduce $\mathrm{R} \& \mathrm{D}$, but it also mitigates the positive effect of $v$. In the $G C E$ and the $H C E, \partial^{2} X / \partial h \partial v>0: h$ and $v$ reinforce the positive effects of each other.

The effects of appropriability on profits and welfare depends on who benefits from information leakages (competitors or vertically related firms) and the prevailing TOC. In all three cooperative equilibria, an increase in $h$ always increases profits, consumer surplus and welfare. This is true even though $\partial X^{V C} / \partial h<0$. In the $N C E, \partial W^{N C} / \partial h_{\varsigma}^{>} 0$ even though $\partial X^{N C} / \partial h<0$. At low levels of $h$, increases in $h$ benefit firms and consumers. This suggests that appropriability problems that induce firms to refrain from innovating are not necessarily undesirable, given that this loss in innovation is more than compensated for by the increase in knowledge received by other firms. For very high levels of $h$, however, the reduction in $R \& D$ is so drastic that welfare suffers. In some cases, firms may be benefiting from the increase in $h$ at the expense of consumers. Thus, the effect of changes in $h$ on welfare depends on its initial level. This analytical ambiguity of the effect of $h$ on prices and costs is in contrast to the empirical finding that spillovers generally induce output expansions and price reductions.

On the other hand, in all TOC, an increase in $v$ always increases profits, consumer surplus, and welfare. These findings are consistent with those of Peters (1995) and Steurs $(1994,1995)$.

\section{Comparison of cooperative structures}

In this section the different types of cooperation are compared in terms of R\&D. This comparison

\footnotetext{
${ }^{20}$ Steurs $(1994,1995)$ finds that the total effect of an increase in intra and interindustry spillovers is ambiguous, and is more likely to be positive for lower levels of spillovers.

${ }^{21}$ Steurs $(1994,1995)$ also finds that spillovers between demand independent industry, although they affect R\&D positively, reinforce the negative effect of intraindustry spillovers.
} 
is important given that in the literature, most studies have focussed on comparing cooperation vs. no cooperation. However, the choices firms face with respect to R\&D cooperation are much more complex than this binary decision. Firms must decide not only whether to cooperate or not, but also with whom to cooperate. Two important potential partners for cooperation are competitors and suppliers/customers. The four types of R\&D cooperation studied in this paper are: no cooperation, horizontal cooperation, vertical cooperation, and generalized (simultaneous horizontal and vertical) cooperation. They have been explained in detail in section 3 .

$R \& D$ cooperation induces firms to internalize the effect of their $R \& D$ expenditures on the profits of their partners. Let a "competitive externality" represent the marginal effect of the R\&D of a firm on the profits of other firms (this effect is generally non-nil, even when there are no spillovers). In this model there are three types of competitive externalities: the horizontal competitive externality $(H)$, the vertical competitive externality $(V)$, and the diagonal competitive externality $(D) . H$ represents the sum of the marginal effects of a firm's R\&D on the profits of its competitors; this externality is internalized in the $H C E$ and the GCE. $H$ can be positive or negative, depending on whether an increase in R\&D by a firm increases or decreases the profits of its competitors. $H$ increases with horizontal spillovers, and generally also with vertical spillovers. $V$ represents the sum of the marginal effects of a firm's R\&D on the profits of its customers/suppliers; this externality is internalized in the $V C E$ and the $G C E$. It is positive, given that an increase in R\&D by a firm always increases the profits of its customers/suppliers. $D$ represents the sum of the marginal effects of a firm's $R \& D$ on the profits of firms in the other industry, which are neither competitors nor customers/suppliers; this externality is always positive, and is internalized in the $G C E$ only. $V$ and $D$ are always positive, but are larger when horizontal and vertical spillovers are higher. No competitive externalities are internalized in the $N C E$. The following lemma characterizes the relation between competitive externalities and the ranking of TOC.

Lemma 1. Let $m=n=2$. Let the horizontal competitive externality $H$ be given by

$$
H \equiv \frac{\partial \pi_{b 2}}{\partial x_{b 1}}+\frac{\partial \pi_{b 1}}{\partial x_{b 2}}+\frac{\partial \pi_{s 2}}{\partial x_{s 1}}+\frac{\partial \pi_{s 1}}{\partial x_{s 2}}
$$

Let the vertical competitive externality $V$ be given by

$$
V \equiv \frac{\partial \pi_{s 1}}{\partial x_{b 1}}+\frac{\partial \pi_{s 2}}{\partial x_{b 2}}+\frac{\partial \pi_{b 1}}{\partial x_{s 1}}+\frac{\partial \pi_{b 2}}{\partial x_{s 2}}>0
$$

Let the diagonal competitive externality $D$ be given by

$$
D \equiv \frac{\partial \pi_{s 2}}{\partial x_{b 1}}+\frac{\partial \pi_{s 1}}{\partial x_{b 2}}+\frac{\partial \pi_{b 2}}{\partial x_{s 1}}+\frac{\partial \pi_{b 1}}{\partial x_{s 2}}>0
$$

Then, between any two TOC, the one internalizing a larger (more positive) sum of competitive externalities will yield more $R \& D$.

Proof. The inclusion of positive (negative) externalities in the first order condition of a firm increases (decreases) its $R \& D$, given that the profit of a firm is concave in its own $R \& D$.

The comparison between $T O C$ rests on the signs and magnitudes of those externalities: the TOC 
yielding more R\&D will be the one which internalizes a larger sum of competitive externalities. ${ }^{22}$ This is because internalizing a positive competitive externality increases $R \& D$, while internalizing a negative competitive externality reduces $\mathrm{R} \& \mathrm{D} .^{23}$ This result is quite general, and can be particularly useful in comparing different cooperative structures even when no closed form solutions exists or that the levels of R\&D investments are not known. In what follows we use those three competitive externalities to analyse the classification of $T O C$.

Before proceeding with the analysis it will be useful to restate the basic result of the strategic investment literature, that with low horizontal spillovers R\&D competition yields more innovation than (horizontal) R\&D cooperation. When $h$ is high, information leakage is important, and firms underinvest. Consequently cooperation induces them to internalize this positive externality, and R\&D is increased. On the other hand, when $h$ is low, information leakage is negligible, and the private gains from $\mathrm{R} \& \mathrm{D}$ outweigh the spillover. Accordingly firms give less weight to the spillover, and overinvest in R\&D. In this context intraindustry cooperation reduces $R \& D$, since firms internalize this negative externality. As the analysis to follow will show, accounting for vertical spillovers and vertical cooperation can seriously alter this result.

The analysis starts in a bilateral duopoly framework, and the effect of market structure is introduced later. The following proposition summarizes the ranking of $T O C$ when $m=n=2$.

Proposition 2. Let $m=n=2$. Then

a) $X^{V C}>X^{N C}$.

b) $X^{G C}>X^{H C}$.

c) $\operatorname{sign}\left(X^{V C}-X^{H C}\right)=\operatorname{sign}(1-h)$.

d) $\operatorname{sign}\left(X^{N C}-X^{G C}\right)=\operatorname{sign}(1-11 h-10 v)$.

e) $\operatorname{sign}\left(X^{N C}-X^{H C}\right)=\operatorname{sign}(13-23 h-10 v)$.

f) $\operatorname{sign}\left(X^{G C}-X^{V C}\right)=\operatorname{sign}(7 h+5 v-2)$.

Proof. These results follow from lemma 1 . They can also be obtained by analysing the differences between total R\&D expenditures under pairs of TOC.

Part $a$ of proposition 2 states that $X^{V C}>X^{N C}$. In the $N C E$ no competitive externality is internalized. In the $V C E$ firms internalize the vertical competitive externality, which is always positive, pushing $R \& D$ up. When $v>0$, firms internalize the effect of their R\&D on the production cost and the profits of their customer/supplier. Even when $v=0$, firms internalize the effect of their own cost reduction on the increase in the size of the market and profits of their customer/supplier, thus increasing their R\&D compared with the NCE.

Part $b$ of proposition 2 compares the $G C E$ with the $H C E$. In all cases $X^{G C}>X^{H C}$. Generalized cooperation internalizes $V, H$, and $D$, while horizontal cooperation internalizes $H$. Taking the difference between the two, $(V+H+D)-H=V+D>0$ : generalized cooperation dominates horizontal cooperation because it internalizes the same horizontal externality (which may be positive or negative, but this is

\footnotetext{
${ }^{22}$ Boivin and Vencatachellum (1998) develop a related concept of a competitive externality given by $\partial y_{j} / \partial x_{i}$. They show that this externality is of the same sign as $\partial \pi_{j} / \partial x_{i}$ when demand is linear.

${ }^{23} \mathrm{I}$ am indebted to Caroline Boivin for suggesting this line of analysis.
} 
irrelevant here) and, in addition, internalizes the positive $V$ and $D$.

Part $c$ of proposition 2 compares $H C$ with $V C$. $V C$ dominates, except when $h=1$, where $X^{V C}=X^{H C}$. $V C$ internalizes $V$, while $H C$ internalizes $H$. When horizontal spillovers are low, $H$ is negative (because an increase in R\&D by a firm reduces the profits of its competitor), therefore $V>H$. But even when horizontal spillovers are high, so that $H>0, V$ is larger than $H$ : the vertical competitive externality internalized through vertical cooperation is larger than the horizontal competitive externality internalized through horizontal cooperation. It is only when $h=1$ that the two TOC yield equal levels of R\&D.

The relation between the $N C E$ and the GCE (part $d$ of proposition 2) depends on the levels of $h$ and $v$. When $h$ and $v$ are very low, $N C$ dominates, because in that case cooperation between competitors reduces $\mathrm{R} \& \mathrm{D}$. The negative horizontal effect dominates the positive vertical and diagonal effects: $|H|>V+D$. When $h$ and $v$ are high, the horizontal competitive externality $(H)$ becomes less negative, and eventually positive, therefore $V+D+H>0$. In that case $X^{G C E}>X^{N C E}$. However, contrary to the established result in the literature, that increase comes for levels of horizontal spillovers much smaller than $h=1 / 2$. In fact, as proposition 2 establishes, even when $h=0, G C$ can increase R\&D. This is due to the presence of the vertical and diagonal competitive externalities, which may dominate the negative $H$ when horizontal spillovers are low.

Part $e$ of proposition 2 states that $X^{N C}>X^{H C}$ when $h$ and $v$ are low, while the inequality is reversed for high spillovers. $H C$ increases $\mathrm{R} \& \mathrm{D}$ compared to $N C$ when $H>0$, that is, when the horizontal competitive externality internalized through horizontal cooperation is positive. As explained above, a low $h$ induces overinvestment in the $N C E$, therefore $H C$ reduces $\mathrm{R} \& \mathrm{D}$; conversely, a high $h$ induces underinvestment in the $N C E$, therefore $H C$ increases R\&D.

The effect of $v$ is novel, however, and needs to be explicited. $H C$ is more likely to increase R\&D when $v$ is high. This result can be understood in terms of the strategic interaction of research efforts. In the NCE and the HCE, buyers' research expenditures are strategic substitutes iff $7>11 h+4 v$, and sellers' research expenditures are strategic substitutes iff $1>2 h+v$. R\&D cooperation between firms whose research efforts are strategic substitutes (complements) decreases (increases) R\&D. $v$ contributes to strategic complementarity between competitors: a higher $v$ increases the benefit a firm extracts from its competitor's R\&D, trough the effect of that R\&D on the cost of the customer/supplier of the firm. For instance, an increase in $x_{b 2}$ benefits $b 1$ directly through $h$, but also indirectly through the reduction in $c_{s l}$ (the cost of the supplier of $b 1$ ) induced by $v$. As vertical spillovers contribute to horizontal strategic complementarity, they reduce the level of horizontal spillovers required for $H C$ to increase R\&D. In other words, with high vertical spillovers, horizontal cooperation can increase R\&D even with low horizontal spillovers. This result is contrary to what is established in the literature, and shows the importance of accounting for vertical spillovers in the analysis of R\&D cooperation.

Part $f$ of proposition 2 states that when spillovers are very low, $V C$ dominates $G C$, while this relation is reversed for moderate and high spillovers. $V C$ internalizes $V$, while $G C$ internalizes, $H, V$ and $D$. Therefore, $X^{G C}>X^{V C}$ iff $H+V+D>V$, i.e. iff $H+D>0$. When spillovers are low, $H$ is negative, and dominates the positive $D$ : the negative effect of internalizing the horizontal competitive externality dominates the positive effect of internalizing the diagonal competitive externality. As horizontal and vertical spillovers increase, $H$ becomes less negative, and eventually positive, therefore for high spillovers $X^{G C}>X^{V C}$. 
The comparisons in proposition 2 have been performed pairwise. It is useful to be able to rank all TOC for given levels of spillovers. Figure 3 illustrates the ranking of $T O C$ in the $h \times v$ space, based on the conditions stated in proposition 2. This figure is divided into 5 regions, each region being characterized by a ranking of the TOC. The following table summarizes the relation between the competitive externalities and the magnitude and sign of $H$ in each region.

[Figure 3 here]

Table 2 - Ranking of types of cooperation

\begin{tabular}{|l|l|l|l|l|l|}
\hline $\begin{array}{l}\text { Region } \\
\text { (fig. 3) }\end{array}$ & Spillovers' values & Ranking of TOC & Competitive externalities & $\begin{array}{l}\text { Magnitude } \\
\text { of } H\end{array}$ & Sign of $H$ \\
\hline Region 1 & $v<(1-11 h) / 10$ & $V C>N C>G C>H C$ & $V>0>V+H+D>H$ & $|H|>V+D$ & $H<0$ \\
Region 2 & $(1-11 h) / 10<v<(2-7 h) / 5$ & $V C>G C>N C>H C$ & $V>V+H+D>0>H$ & $|H|>D$ & $H<0$ \\
Region 3 & $(2-7 h) / 5<v<(13-23 h) / 10$ & $G C>V C>N C>H C$ & $V+H+D>V>0>H$ & $|H|<D$ & $H<0$ \\
Region 4 & $v>(13-23 h) / 10, h \neq 1$ & $G C>V C>H C>N C$ & $V+H+D>V>H>0$ & $H<V$ & $H>0$ \\
Region 5 & $h=1$ & $G C>V C=H C>N C$ & $V+H+D>V=H>0$ & $H=V$ & $H>0$ \\
\hline
\end{tabular}

Region 1 is characterized by low spillovers. In this region $V C>N C>G C>H C$. $H$ is negative and sufficiently large to cause the $G C E$ to reduce R\&D compared to the $N C E$. As spillovers increase, we move into region 2, where the ranking of $G C$ and $N C$ is reversed: $V C>G C>N C>H C$. $H$ is still negative enough to outweigh $D$ (therefore $X^{G C}<X^{V C}$ ), but not negative enough to outweigh $V+D$ (therefore $X^{G C}>X^{N C}$ ). As spillovers increase further, we move into region 3, where $G C$ comes to dominate all other TOC. $H$ is still negative, but is smaller than $D$, therefore $X^{G C}>X^{V C}$. When spillovers increase further, we move into region 4: the horizontal competitive externality becomes positive, therefore $X^{H C}>X^{N C} \cdot{ }^{24}$ Finally, when $h=1$ (region 5), and independently of $v$, the horizontal competitive externality increases further: $H=V$, therefore $X^{H C}=X^{V C}$.

As we move north-east (i.e. as spillovers increase), the ranking of $V C$ and $N C$ deteriorates, while the ranking of $G C$ and $H C$ improves. It is surprising that as vertical spillovers increase, the ranking of $V C$ deteriorates, as it becomes dominated by $G C$, which has the advantage of allowing competitors to cooperate, and of inducing a firm to internalize the effect of its $R \& D$ on all the firms in the other industry, and not only on its own supplier/customer (as would be the case with $V C$ ). Note that for the largest part of the spillovers space, $G C$ dominates all other $T O C$, followed by $V C$. This shows the importance of interindustry cooperation, whether there is intraindustry cooperation or not. $V C$ is a

\footnotetext{
${ }^{24}$ Note that at $v=0$ and $h=1 / 2, X^{N C}>X^{H C}$, while the literature would predict equality between the two TOC in that case. The reason is that in this model buyers and sellers have different conditions of strategic interaction (as specified above). The line determining strategic interaction for buyers $(7-11 h-4 v)$ in the NCE and the HCE lies slightly to the right of the line separating regions 3 and 4 (13-23h-10v), while the line determining strategic interaction for sellers (1-2h-v) lies slightly to the left of that line. In fact, the line separating regions 3 and 4 can be expressed as a linear combination of the lines determining strategic interaction for buyers and sellers, since $(7-11 h-4 v)+6(1-2 h-v)=13-23 h-10 v$. Therefore, at $v=0$ and $h=1 / 2$, the passage from $N C$ to $H C$ does not change sellers' R\&D, but decreases buyers' R\&D, therefore total R\&D decreases. On the line separating regions 3 and 4 , the passage from $N C$ to $H C$ increases sellers' R\&D and decreases buyers' R\&D by offsetting amounts.
} 
complement, not a substitute, to $H C{ }^{25}$

Many important results emerge from the preceding analysis. First, one of the basic results of the strategic investment literature is that cooperation between competitors increases (decreases) $R \& D$ when horizontal spillovers are high (low). The model shows that this result does not necessarily hold when vertical spillovers and vertical cooperation are taken into account. It is necessary to account for the horizontal, vertical, and diagonal internalization effects in comparing different types of $R \& D$ cooperation. Second, even if all forms of cooperation do not always increase R\&D compared with the $N C E$, in all cases, at least one form of cooperation does. The only form of cooperation always (strictly) dominating the $N C E$ is $V C$. The question of whether cooperation is desirable or not has to be addressed with reference to specific cooperative schemes. Third, no TOC constantly dominates the others. The relative efficiency of different $T O C$ cannot be studied without explicit reference to appropriability. This suggests that optimal structures may vary $i$ ) across industries, $i i$ ) within the same industry, for different technologies having different appropriability characteristics, and iii) over time for a given industry, as technology changes. Finally, comparing parts $a$ and $e$ of proposition 2 shows that there is an important asymmetry between $H C$ and $V C$. $V C$ is beneficial irrespective of the level of spillovers, whereas whether $H C$ is beneficial depends on both horizontal and vertical spillovers. This is because the vertical internalization effect is always positive, while the horizontal internalization effect may be positive or negative.

The comparison between $T O C$ has been performed in a bilateral duopoly case. A legitimate question is how sensitive are the results to this specific market structure. As the analysis to follow shows, market structure affects the size of the gap between $\mathrm{R} \& \mathrm{D}$ expenditures, and affects the tradeoff between horizontal and vertical cooperation. To answer that question, we perform the comparison between TOC for a more general market structure: $m=n \in[1,20]$. While it is possible to study this question for all levels of $m$ and $n$ within the space defined above, the $V C E$ requires $m=n$. For the purpose of comparability between $T O C$, the analysis is restricted in this section to the case $m=n$. Moreover, in order to reduce the dimensionality of the problem, the analysis is restricted to polar appropriability environments: no spillovers $(h=v=0)$, perfect spillovers $(h=v=1)$, perfect horizontal spillovers only $(h=1, v=0)$, and perfect vertical spillovers only $(h=0, v=1)$. For brevity's sake let $(h, v)$ represent appropriability conditions. For each polar case of spillovers, $\mathrm{R} \& \mathrm{D}$ is ranked across $T O C$, allowing for a variable market structure. Numerical simulations are used to compare (not to generate, therefore there is no loss of generality) elaborate analytical expressions. ${ }^{26}$ While it is possible to compare directly the analytical expressions, numerical simulations make the presentation of results, and the comparison between different TOC much smoother. Figure 4 compares TOC for a given appropriability environment. ${ }^{27}$

[Figure 4 here]

\footnotetext{
${ }^{25}$ This is in accord with the following quote by Jorde and Teece: "Successful new product and process development innovation often requires horizontal and lateral as well as vertical cooperation." (Jorde and Teece, 1990:81). Jorde and Teece (1992) note that horizontal and hybrid (horizontal + vertical) cooperative arrangements face a larger degree of uncertainty from US antitrust laws.

${ }^{26}$ Numerical simulations are based on the numerical parameterization specified in note 17.

${ }^{27}$ On figure 4 curves may overlap for some values of $m$ and $n$. The labelling of curves corresponds to their ranking at $m=n=20$, but not necessarily to their ranking at other values of $m$ and $n$.
} 
The ranking of $T O C$ at $m=n=2$ on figure 4 is consistent with proposition 2 , and will not be discussed again. However, two important insights come from the analysis of a more general market structure. First, figure 4 illustrates an important distinction between horizontal and vertical cooperation in terms of the magnitudes of the increases and reductions in R\&D investments (compared to the $N C E$ ) they cause. $V C$ always increases $\mathrm{R} \& \mathrm{D}$, while $H C$ may increase or decrease $\mathrm{R} \& \mathrm{D}$. However, when $H C$ is beneficial, its benefits compared with the $N C E$ are much larger than the benefits of $V C$, which are marginal. Formally, in general $\left|X^{H C}-X^{N C}\right|>\left|X^{V C}-X^{N C}\right|$. This is because the internalization of horizontal spillovers changes the sign of the externality, whereas the internalization of $v$ merely reinforces its (always positive) effect, without changing its sign. Therefore, even though $V C$ is always beneficial, it is generally only marginally so. In contrast, when $H C$ is beneficial, its benefits are substantial. ${ }^{28}$

Second, as figures $4 \mathrm{~b}$ and $4 \mathrm{~d}$ show, when $h=1, X^{V C}=X^{H C}$ for $m=n=2$, but $X^{V C}<X^{H C}$ for all $m=n>2$. Therefore the result obtained above that in the bilateral duopoly case $X^{V C} \geq X^{H C}$ is heavily dependent upon market structure. With $m=n=2$, horizontal effects are negligible because of the small number of firms, and the two TOC yield equal amounts of R\&D. However, as competition intensifies the importance of the horizontal externality increases, and $H C$, which internalizes this externality, gains in importance. To see that, note that in a market with $m=n$ firms in each industry, the number of terms constituting $H$ is $2 m(m-1)$, while the number of terms constituting $V$ is $2 m$. As $m$ increases, the number of terms constituting $H$ grows much more rapidly (of course the magnitudes of the terms matter, but their number is indicative of the relative importance of the two effects). Thus, the model provides a preliminary answer to the question of which is more socially beneficial between horizontal and vertical cooperation. When horizontal spillovers are low, $V C$ yields more $\mathrm{R} \& \mathrm{D}$ than $H C$. When horizontal spillovers are high, the result depends on market structure: $V C$ tends to dominate when $m=n=2$, but $H C$ yields more R\&D for $m=n>2$ (moreover, with high concentration $H C$ is more likely to lead to collusion, but this is outside the scope of the model).

This result shows the importance of analysing the effect of market structure on the relative desirability of different TOC. For instance, Steurs (1995), who studies spillovers and cooperation between demand unrelated industries, finds that whether interindustry cooperation is more or less beneficial depends on spillovers: interindustry cooperation is likely to be more beneficial than intraindustry cooperation when interindustry spillovers are high and intraindustry spillovers are low. Here, it is also true that interindustry cooperation is more beneficial when intraindustry spillovers are low. However, when intraindustry spillovers are high, the result depends on market structure.

A related question is how cooperation affects welfare. Overall there is a monotonic relation between R\&D spending and welfare. A notable exception is when there are no spillovers, where firms tend to overspend on R\&D compared with the social optimum ${ }^{29}$ in the $N C E$ and the VCE. Namely, firms

\footnotetext{
${ }^{28}$ The same can be said about GC. Moreover, the dominance of the diagonal effect -which may induce cooperation between competitors to increase innovation even with a low $h$ - on direct vertical effects can be seen from the large difference between $X^{G C}$ and $X^{N C}$, compared with the small difference between $X^{V C}$ and $X^{N C}$, on figure 4c.

${ }^{29}$ The social optimum could be defined with respect to the levels of output and R\&D maximizing the sum of producer and consumer surplus. However, Suzumura (1990) questions the relevance of this "first best" outcome, since governments may have more latitude in affecting firms' R\&D decisions than in affecting their output decisions. Suzumura adopts a "second best" concept of the social optimum, where welfare is maximized with respect to R\&D, but not with respect to output. This second best social optimum concept is used here.
} 
overspend on $\mathrm{R} \& \mathrm{D} i$ ) in the $N C E$, with no spillovers, $\min \{m, n\} \geq 3$ or $\{m=2, n \geq 5\}$ or $\{m \geq 5, n=2\}$, and ii) in the $V C E, m=n \geq 3$ with no spillovers. ${ }^{30}$ Consumer surplus is always higher than in the social optimum when there is overspending on R\&D. However, one should be cautious before exaggerating the importance of overspending on R\&D. First, the -static- modelization does not necessarily exhaust all the -static and dynamic- benefits of R\&D. Second, empirical studies suggest that usually there is underinvestment, not overinvestment, in R\&D. ${ }^{31}$ Third, the model shows that overspending occurs less often, and in smaller magnitudes, than underspending. Finally, although total welfare suffers from this overspending on R\&D, consumers benefit from it.

Spillovers increase the social gains from cooperation. With high spillovers the $N C E$ is more likely to be dominated by other $T O C$, whereas the $N C E$ generally dominates (in terms of welfare, at least) without spillovers. Moreover, by analysing the gap between the NCE and the other TOC, we see that spillovers increase the value of cooperation, for they increase the inefficiency of the NCE compared with the social optimum (this is clear form figure 4).

The interactions between $h$ and $H C$ can be understood in terms of the business strategies taxonomy of Tirole (1989) (see table 3). When $h$ is low and there is no $H C$ or $G C$, firms adopt a top dog strategy: R\&D investments make the investing firm look tough, by improving its competitive position. Moreover, in that case reaction functions between competitors are downward sloping, ${ }^{32}$ and this increase in R\&D by firm $i$ reduces R\&D by its competitors. When $h$ is low and there is $H C$ or $G C$, firms adopt a puppy dog strategy: each firm reduces its R\&D investments, so as to be inoffensive, given that firms are cooperating. ${ }^{33}$ In that case research efforts within industries are strategic complements, and this reduction in $\mathrm{R} \& \mathrm{D}$ reduces competitors' $\mathrm{R} \& \mathrm{D}$ as well. With high $h$ and no $H C$ or $G C$, firms adopt a lean and hungry look: because investments benefit competitors, firms underinvest to be tough. Given that in that case research efforts within industries are strategic complements, this underinvestment reduces competitors' R\&D as well. Finally, with high $h$ and $H C$ or $G C$, firms adopt a fat cat strategy: they want to look inoffensive, given that they are cooperating; and the best way to achieve that is to invest heavily in $R \& D$, which benefits competitors. And given that reaction functions are upward sloping in this case, this overinvestment is matched by overinvestment from competitors.

\footnotetext{
${ }^{30}$ This is not the first study to identify instances of overspending on R\&D. Suzumura (1992) finds that firms overspend on $R \& D$ with no spillovers in the non-cooperative equilibrium (in a one-industry model) when the number of firms is large. Dasgupta and Stiglitz (1980) find that when demand is highly inelastic and that free entry is allowed, R\&D spending may exceed the socially optimal level. Bester and Petrakis (1993), in a model of cost reduction with no spillovers, find that overinvestment in R\&D may occur when goods produced by different firms are close substitutes.

${ }^{31}$ On the input side, Canada, for instance, devotes a relatively low proportion of its resources to R\&D compared to most OECD countries. On the output side, studies typically find that the social rate of return on R\&D is much higher than the private rate of return.

${ }^{32}$ It can be easily shown (when $m=n=2$ ) that in the $N C E$ and the $H C E$, buyers' research expenditures are strategic substitutes iff $7>11 h+4 v$, and sellers' research expenditures are strategic substitutes iff $1>2 h+v$. In the GCE and the $V C E$, buyers' research efforts are strategic substitutes iff $-71+182 h-71 h^{2}+40 v+40 h v+40 v^{2}<0$ and sellers' research expenditures are strategic substitutes iff $-11+32 h-11 h^{2}+10 v+10 h v+10 v^{2}<0$. These inequalities imply that horizontal and vertical spillovers induce strategic complementarity between competitors, and that buyers' research expenditures are more likely to be strategic substitutes than sellers' research expenditures. Moreover, research efforts between buyers and sellers are strategic complements in all TOC.

${ }^{33}$ As figure $4 \mathrm{c}$ shows, this result may be slightly altered by the presence of vertical spillovers.
} 
Table 3- Business strategies, cooperation and spillovers

\begin{tabular}{|c|cc|}
\hline & $H C$ or $G C$ & $N C$ or $V C$ \\
\hline Low $h$ & puppy dog & top dog \\
High $h$ & fat cat & lean and hungry look \\
\hline
\end{tabular}

\section{Market Structure and innovation}

The relation between competition and innovation can be affected by many factors. One such factor is the technological environment of the industry. In this model the technological environment is characterized by appropriability (horizontal and vertical spillovers) and R\&D cooperation. We use the model to analyze how the technological environment affects the relation between competition and innovation. Moreover, by analysing the upstream and downstream simultaneously, one can assess how competition and technological opportunities in vertically related markets affect innovation. As Peters (2000:13) notes: "the conditions on vertically related markets also determine the innovative activities of firms".

For the sake of simplicity this analysis is performed for the four polar appropriability environments described in section 5 : $(0,0),(1,0),(0,1),(1,1)$. With four TOC and four appropriability environments, there are 16 different relations between market structure and R\&D. These 16 different relations can be grouped under three types of relations, shown in figure 5. The vertical axis measures total R\&D output, and the horizontal axes measure industry sizes.

\section{[Figure 5 here]}

Figure 5a depicts a positive relation between competition and R\&D: both symmetric and asymmetric increases in competition increase R\&D. I call this relationship the Competitive model, and refer to it as $C$. Figure 5b depicts a negative relationship between competition and R\&D along the $\operatorname{diagonal}^{34}$ as well as for asymmetric increases (except when at least one industry is highly concentrated, where the asymmetric effect may be positive). I call this relationship the Schumpeterian model, and refer to it as $S$. Figure 5c depicts a rather odd relationship between competition and R\&D. A symmetric increase in the size of the two industries increases R\&D; an asymmetric increase in $m$ (holding $n$ constant) increases R\&D for low $n$ and decreases R\&D for high $n$; similarly, an asymmetric increase in $n$ (holding $m$ constant) increases R\&D for low $m$ and decreases $\mathrm{R} \& \mathrm{D}$ for high $m$. In this configuration, $\mathrm{R} \& \mathrm{D}$ is maximized when the market structure is very asymmetric. I call this relationship the Asymmetric model, and refer to it as $A$.

Table 4 shows the correspondence between couples of cooperation and appropriability, and the relations described above. No row and no column gives uniformly the same result, implying that the effect of competition on R\&D cannot be predicted without specifying both the appropriability conditions of the market and the prevailing type of cooperation. In the case of the VCE, the result is determined along the diagonal $m=n$, because asymmetric market structures are not allowed. Hence, for the $V C E$,

\footnotetext{
${ }^{34}$ Except from the move from a bilateral monopoly to a bilateral duopoly. This suggests that, even if it can be argued that competition may hinder innovation in some cases, any competition level less than a duopoly reduces innovation.
} 
an increasing $\mathrm{R} \& \mathrm{D}$ along this diagonal indicates either the relation $C$ or the relation $A$ (it is impossible to differentiate between the two), while a decreasing R\&D indicates the relation $S$.

Note the following regularities. Comparing columns, we see that the $N C E$ and the VCE yield the same results (subject to the impossibility of distinguishing between $C$ and $A$ under $V C$ ). Moreover, $G C$ and $H C$ yield closely related results, with the difference that $C$ under $H C$ is replaced by $A$ under $G C$. Comparing rows, we see that the cases $(1,1)$ and $(1,0)$ yield similar results. Finally, note that $A$ obtains only with $G C$.

Table 4 - Effect of competition on total R\&D spending

\begin{tabular}{|l|cccc|}
\hline & $\begin{array}{c}\text { No } \\
\text { cooperation }\end{array}$ & $\begin{array}{c}\text { Generalized } \\
\text { cooperation }\end{array}$ & $\begin{array}{c}\text { Horizontal } \\
\text { cooperation }\end{array}$ & $\begin{array}{c}\text { Vertical } \\
\text { cooperation }\end{array}$ \\
\hline No spillovers $(0,0)$ & $\mathrm{C}$ & $\mathrm{S}$ & $\mathrm{S}$ & $\mathrm{C}$ or A \\
$\begin{array}{l}\text { Perfect horizontal spillovers } \\
\text { No vertical spillovers }(1,0)\end{array}$ & $\mathrm{S}$ & $\mathrm{A}$ & $\mathrm{C}$ & $\mathrm{S}$ \\
$\begin{array}{l}\text { Perfect vertical spillovers } \\
\text { No horizontal spillovers }(0,1)\end{array}$ & $\mathrm{C}$ & $\mathrm{A}$ & $\mathrm{C}$ & $\mathrm{C}$ or A \\
Perfect spillovers $(1,1)$ & $\mathrm{S}$ & $\mathrm{A}$ & $\mathrm{C}$ & $\mathrm{S}$ \\
\hline \multicolumn{2}{|l|}{$C$ : Competitive; $S:$ Schumpeterian; $A:$ Asymmetric } & & \\
\hline
\end{tabular}

The change in market structure can take two forms: a simultaneous increase in the number of firms in both industries, or an increase in the number of firms in one industry only. Consider first a simultaneous increase in the number of firms in the two industries. The result will be stated in terms of the horizontal competitive externality, $H$. Remember that $H$ represents the sum of the marginal effects of a firm's R\&D on the profits of its competitors; this externality is internalized in both the HCE and the $G C E$. $H$ can be positive or negative, depending on whether an increase in R\&D by a firm increases or decreases the profits of its competitors. In general, $H$ is more likely to be positive the higher horizontal and vertical spillovers are.

Proposition 3. Let $k=m=n>2$ (an increase in $k$ is a north-east move along the diagonal in figure 5, and corresponds to a simultaneous and equal increase in the number of firms in the two industries). Let $h, v \in\{0,1\}$. Let $\lambda=1$ if there is intraindustry cooperation (HC or GC) and let $\lambda=0$ otherwise (NC or VC). Then

This implies that:

$$
\operatorname{sign}(\partial X / \partial k)=\operatorname{sign}(1+2 v(1-h)-2|\lambda-h|) .
$$

3a. When $h=1$ or $v=0$ (the first, second, and fourth rows of table 4) $\partial X / \partial k$ is of the opposite sign of the horizontal competitive externality when that externality is not internalized, and is of the same sign as the horizontal competitive externality when that externality is internalized.

$3 b$. When $h=0$ and $v=1$ (the third row of table 4 ), $\partial X / \partial k>0$.

The intuition is as follows. Consider first part $a$ of proposition $3 .{ }^{35}$ When a negative competitive horizontal externality is not internalized, $\mathrm{R} \& \mathrm{D}$ serves mainly as a competitive tool. Hence $\partial X / \partial k>0$ : as

\footnotetext{
${ }^{35}$ In these cases $\operatorname{sign}(\partial X / \partial k)$ is determined solely by horizontal effects (which may be positive or negative); vertical effects (which are always positive) are always dominated by horizontal effects.
} 
competition intensifies, firms use more of this competitive tool (each firm's R\&D declines, but total R\&D increases). When the negative competitive horizontal externality is internalized, however, firms use $R \& D$ to increase the total size of the market, benefiting all from this expansion. However, they do not aim at hurting each other through R\&D. Hence an increase in $k$, which increases the effects of the negative externality, reduces R\&D. Similarly, when a positive competitive horizontal externality is not internalized, the main effect of R\&D is to benefit competitors. Hence an increase in competition increases the effect of this positive externality on competitors, and R\&D decreases. When this positive competitive externality is internalized, however, firms maximize the benefits from it as $k$ increases, and total R\&D increases.

Consider now part $b$ of proposition 3. Because $v$ is very large compared to $h$, its positive impact implies that $\partial X / \partial k>0$. Horizontal effects are still present, but small: when negative they are dominated by vertical effects; when positive they reinforce vertical effects. ${ }^{36}$ It is specifically in this case that the effect of vertical spillovers on the relationship between competition and innovation is most explicit.

Note that whereas the effect of $h$ depends on whether it is internalized or not, the effect of $v$ is independent of its internalization. This is because the internalization of $h$ changes the sign of the externality, whereas the internalization of $v$ merely reinforces its (always positive) effect, without changing its sign.

Proposition 3 dealt with the effects of symmetric increases in industry sizes. Consider now the effects of an asymmetric increase in industry size. The fourth column of table 4 is irrelevant here, because asymmetries are not allowed under $V C$. An asymmetric increase in competition has a positive effect on R\&D under $C$, a generally negative effect under $S$, and an ambiguous effect under $A$. The asymmetric effects in the $C$ and $S$ model can be understood by using the same analysis as for symmetric increases in competition. With either $h=1$ or $v=0$, the effect of horizontal externalities dominates. Hence the effect of an asymmetric increase in industry size is of the same sign as the horizontal competitive externality if it is internalized, and is of inverse sign if that externality is not internalized. In the fourth case, $(0,1)$, the result is determined by vertical effects, which are always positive.

The asymmetric effects under the $A$ model can be understood in terms of the vertical and diagonal competitive externalities. As mentioned earlier, the asymmetric increase in industry size in this case has an ambiguous effect on R\&D: it is positive when the other industry is highly concentrated, and negative when the other industry is highly competitive. This implies, as figure $5 \mathrm{c}$ shows, that R\&D is maximized when one industry is highly concentrated, and the other is highly competitive. The reason for this asymmetric outcome is that in the $A$ model, the fringe spends more on R\&D relative to asymmetric market structures in the $C$ or the $S$ models. Indeed, in the $A$ cases, when one industry becomes highly concentrated, the increase in total R\&D comes mainly from the fringe, not from the concentrated industry. The intuition is as follows. The profits of firms in the concentrated industry are higher than profits of firms in the fringe. With $G C$, firms maximize joint profits. Firms in the concentrated industry benefit more from R\&D by the fringe the higher spillovers are. With any type of spillovers present, and with $G C$, because of the large marginal profits of the concentrated industry, the fringe spends more on

\footnotetext{
${ }^{36}$ The often positive effects of competition in this model should be qualified by the fact that the model does not incorporate fixed costs to R\&D.
} 
$R \& D$, given that joint profits are maximized. Moreover, given diseconomies of scale in $R \& D$, substantial collective benefits from $R \& D$ (high spillovers), and asymmetric market structures, total $R \& D$ costs are minimized when the fringe undertakes more $R \& D$ than the concentrated industry. In a sense, the fringe gets exploited by the concentrated industry, and it is happy to be so. Indeed, by comparing profits, we see that the ratio of profits of each firm in the concentrated industry to the profits of each firm in the fringe is highest with the Asymmetric model. With no spillovers, this effect does not arise, because the benefit of the concentrated industry from the fringe's R\&D is more limited. ${ }^{37}{ }^{38}$ The Asymmetric model obtains only with $G C$, because this is the only TOC internalizing simultaneously vertical and diagonal competitive externalities.

To summarize, the relation between competition and innovation can be understood in terms of the three competitive externalities. When $H$ dominates, the effect of competition on innovation is of the same sign as that externality if it is internalized, and of the opposite sign if it is not internalized. When $V$ dominates, the effect of competition is always positive. When $D$ dominates (and that it is internalized), it is generally the Asymmetric model that prevails.

The effect of competition on innovation in a given industry cannot be fully understood without specifying the appropriability conditions and the cooperative relations in the industry as well as in adjacent industries. Teece (1992) suggests that "Discussions of the link between firm size and innovation are outmoded because the boundaries of the firm have become fuzzy", due to strategic alliances. Our model shows that strategic alliances can alter the relation between market structure and innovation, but in no way does the question become obsolete.

Changes in total R\&D may hide important different sectoral effects. Upstream and downstream R\&D expenditures may move in different directions. For instance, starting from a symmetric market structure, an equal increase in the size of the two industries increases the share of buyers in total R\&D in the $N C E$ and the $H C E$. With an asymmetric market structure each firm in the more concentrated industry spends more than each firm in the less concentrated industry. ${ }^{39}$ A similar result is obtained by Peters (1995). The fruits of innovation by the (more) competitive industry accrue mainly to the oligopolistic industry, because of the limited market power of firms in the competitive industry. ${ }^{40}$ This

\footnotetext{
${ }^{37}$ Peters (2000) finds that in the German automobile industry, a higher supplier concentration reduces (stimulates) R\&D intensity if buyer markets are lowly (highly) concentrated. In the model studied here, the relation between competition and R\&D intensity hinges on spillovers and R\&D cooperation. An increase in the number of competitors of a firm increases (decreases) its R\&D intensity when spillovers are high (low) in the $N C E$ and the $V C E$. Spillovers have the opposite effect in the $G C E$ and the $H C E$.

${ }^{38}$ Peters (2000) finds that in the German automobile industry, a small number of suppliers and a large stock of customers stimulate innovative activities. He interprets this outcome in terms of reduced risk for sellers from the opportunistic behaviour of buyers when the latter are in large number, and in terms of the positive effect of buyers' number on the potential utilization of the innovation and the speed of adoption of new technologies. The model proposes an alternative explanation: asymmetric market structures maximize innovative activities when there is generalized cooperation and there are spillovers.

${ }^{39}$ Poyago-Theotoky (1996) shows that the relation between firm size and cost reduction incentives hinges on the way R\&D affects production costs. When costs are affected in an additive (multiplicative) way, large/low cost (small/high cost) firms spend more (these results were derived between competitors, with no vertical linkages).

${ }^{40}$ Terleckyj (1974) provides an illustration of this situation, where the productivity growth of the airline industry was mainly due to the introduction of quality aircraft by the (competitive) aircraft manufacturing industry. Vanderwerf (1992) finds that in the commodity materials-using production processes, more concentrated upstream firms are the source of more downstream innovations when upstream firms are more concentrated, and when downstream firms are less concentrated. This is consistent with
} 
asymmetry in the distribution of the benefits of $R \& D$ is reinforced by, but does not require, vertical spillovers. Regarding the effect of spillovers, an increase in (either type of) spillovers increases the share of the more concentrated industry in the NCE, and reduces it in all other TOC.

\section{Private incentives for cooperation}

This section addresses the private incentives for cooperation. ${ }^{41}$ The question is: under a decentralized negotiation mechanism, do firms, and under what circumstances, decide to cooperate? And when they do, do they choose the socially optimal type of cooperation? This question is important, because regulators need not provide incentives for $\mathrm{R} \& \mathrm{D}$ cooperation when cooperation arises from decentralized negotiations. Moreover, regulators need not prohibit cooperation when firms have no interest in cooperating. In some cases, however, incentives or prohibition may be necessary.

First firms' profits across different $T O C$ are ranked based on numerical simulations. For the sake of simplicity, this analysis is performed in the case $m=n=2$. Tables 5 and 6 present the ranking of profits of buyers and sellers across $T O C$ for different appropriability environments.

The comparison of profits shows that firms will always prefer to cooperate, even though they may have different preferences as to the choice of a TOC. Some forms of cooperation can cause losses to firms compared with the NCE. Buyers generally prefer the $H C E$, except when there are only vertical spillovers, in which case they prefer the $V C E$. Sellers always prefer the $G C E$. Buyers generally prefer $H C$ to $V C$, whereas sellers, in contrast, always prefer $V C$ to $H C$.

The explanation of these divergent preferences lies in the asymmetric distribution of $\mathrm{R} \& \mathrm{D}$ between the two industries. In this model there is a general tendency for buyers to spend less on $R \& D$ than sellers when there is no interindustry cooperation (i.e. under $N C$ and $H C$ ). This tendency of upstream firms to do more $R \& D$ than downstream firms is rooted at the heart of the vertical market structure. It is a fundamental property of vertical structures with equal numbers of buyers and sellers that sellers' profits are always higher than buyers'. Moreover, the marginal effect of a dollar of R\&D on profits is higher for sellers than for buyers. In a vertical market without $R \& D$, with linear demand, constant marginal costs (but not necessarily equal between buyers and sellers), quantities as strategic variables, $m=n$, and $\alpha \equiv \pi_{b i} / \pi_{s i}$, it is straightforward to verify that $\alpha=n /(n+1) .{ }^{42}$ When $\mathrm{R} \& \mathrm{D}$ is added to the model the ratio becomes more complicated, but it remains true that $\alpha<1$ and $\lim _{n \rightarrow \infty} \alpha=1$. As $m=n$ grow the asymmetries in profits and in profits' sensitivity to changes in parameters become negligible, reducing the asymmetries in behaviour between buyers and sellers. Therefore, when taking their decisions independently from sellers $(N C$ or $H C$ ), buyers spend less on R\&D than sellers, because they make less profits. With $V C$ or $G C$, buyers are forced to take into account the effect of their R\&D on sellers' profits,

\footnotetext{
the predictions of the model regarding the relation between concentration and R\&D. Here, however, upstream firms cannot originate downstream innovations as such.

${ }^{41}$ Some studies endogenize the formation and the stability of research joint ventures (De Bondt et al., 1992; PoyagoTheotoky, 1995; Kamien and Zang, 1993; Eaton and Eswaran, 1997; Kesteloot and Veuglelers, 1995; Yi, 1998).

${ }^{42}$ The higher profitability of sellers does not hold for all strategic variables. For instance, when firms use a percentage mark-up rule for pricing, downstream firms make more profits (Irmen, 1997). Moreover, Choe (1998) shows that with a general demand, $\alpha=n /(n+1+\theta)$, where $\theta$ is the quantity elasticity of the slope of the retail demand function.
} 
and this induces an increase in buyers' $\mathrm{R} \& \mathrm{D}$, and a decrease in sellers' $\mathrm{R} \& \mathrm{D} .^{43}$

Table 5 - Ranking of buyers' profits (based on numerical simulations)

\begin{tabular}{|l|cccc|}
\hline & $\begin{array}{c}\text { No } \\
\text { cooperation }\end{array}$ & $\begin{array}{c}\text { Generalized } \\
\text { cooperation }\end{array}$ & $\begin{array}{c}\text { Horizontal } \\
\text { cooperation }\end{array}$ & $\begin{array}{c}\text { Vertical } \\
\text { cooperation }\end{array}$ \\
\hline No spillovers $(0,0)$ & 2 & 3 & 1 & 4 \\
\hline $\begin{array}{l}\text { Perfect horizontal spillovers } \\
\text { No vertical spillovers }(1,0)\end{array}$ & 4 & 2 & 1 & 3 \\
\hline $\begin{array}{l}\text { Perfect vertical spillovers } \\
\text { No horizontal spillovers }(0,1)\end{array}$ & 3 & 4 & 2 & 1 \\
\hline Perfect spillovers $(1,1)$ & 4 & 2 & 1 & 3 \\
\hline
\end{tabular}

Table 6 - Ranking of sellers' profits (based on numerical simulations)

\begin{tabular}{|l|cccc|}
\hline & $\begin{array}{c}\text { No } \\
\text { cooperation }\end{array}$ & $\begin{array}{c}\text { Generalized } \\
\text { cooperation }\end{array}$ & $\begin{array}{c}\text { Horizontal } \\
\text { cooperation }\end{array}$ & $\begin{array}{c}\text { Vertical } \\
\text { cooperation }\end{array}$ \\
\hline No spillovers $(0,0)$ & 4 & 1 & 5 & 1 \\
\hline $\begin{array}{l}\text { Perfect horizontal spillovers } \\
\text { No vertical spillovers }(1,0)\end{array}$ & 5 & 1 & 4 & 3 \\
\hline $\begin{array}{l}\text { Perfect vertical spillovers } \\
\text { No horizontal spillovers }(0,1)\end{array}$ & 5 & 1 & 4 & 3 \\
\hline Perfect spillovers $(1,1)$ & 5 & 1 & 4 & 3 \\
\hline
\end{tabular}

To illustrate this result consider the move from $H C$ to $V C$. For all polar cases of spillovers, sellers gain from this move; and for all polar cases of spillovers except $(0,1)$, buyers lose. The explanation is as follows. Consider first the case (0,0). In this case $x_{b i}^{H C}<x_{s i}^{H C}$, and $x_{b i}^{V C}=x_{s i}^{V C}$. Moreover, $x_{b i}^{H C}<x_{b i}^{V C}$ and $x_{s i}^{H C}<x_{s i}^{V C}$. These inequalities imply that $\mathrm{R} \& \mathrm{D}$ increases for all firms with the move from $H C$ to $V C$, but increases more for buyers. This increase in total R\&D triggers an output expansion. However, this output expansion is marginal, because the decline in the transfer price and in the final price are small. Moreover, the sellers' margin is higher, and they benefit more from this output expansion. Hence, buyers benefit less from this output expansion, and have to bear a larger increase in R\&D costs than sellers. It turns out that the higher additional revenues of sellers are sufficient to cover their modest increase in R\&D, but that the small increase in buyers' revenues is insufficient to cover their large increase in $\mathrm{R} \& \mathrm{D}$. Therefore buyers' profits decline and sellers' profits increase in the passage from $H C$ to $V C$ with spillovers $(0,0)$.

Consider next the cases $(1,0)$ and $(1,1)$. In these cases $x_{b i}^{H C}<x_{s i}^{H C}$, and $x_{b i}^{V C}=x_{s i}^{V C}$. However, $X^{V C}=X^{H C}$. Hence total $R \& D$ remains unchanged but buyers increase, and sellers decrease, their $R \& D$. The size of the market is hardly affected, and buyers have to spend more on R\&D. Naturally, their profits fall compared to $H C$, while sellers, who reduce their R\&D, see their profits increase.

Finally, this result does not obtain in the case $(0,1)$. In this case, the importance of $v$ relative to

\footnotetext{
${ }^{43}$ This explains also why in all cases where buyers prefer $H C$ to $V C$, they prefer $G C$ to $V C$ : $G C$, while implying some form of vertical cooperation, also incorporates horizontal cooperation.
} 
$h$ makes $V C$ beneficial to all firms. And given that $h$ is very low, $H C$ is not particularly attractive.

Buyers' lower innovation is a consequence -not a cause- of their lower profitability, which is due to the structure of the output market. By cooperating on technology with sellers, buyers are attacking the symptom rather than the cause of their inferior position. Technological cooperation, while it increases buyers' innovation, reduces their profits, because it forces them to align their innovation rate on more innovative, more powerful, and more profitable firms. Total profits increase with cooperation, but the redistribution of profits is in favour of sellers and at the expense of buyers. This result illustrates how firms seeking technological agreements to solve deeper problems may exasperate these problems instead of alleviating them.

Using firms' profits, the stability of cooperation is now analysed. We look for the TOC which firms would agree upon for each appropriability environment. This game can be seen as an initial stage being played before the three-stage game involving R\&D, upstream output, and downstream output, is played. The strategies at this stage are $T O C$. Each industry chooses a TOC, given appropriability. If the two industries agree on a TOC, this setting is implemented. If no TOC constitutes a Nash equilibrium, the NCE is implemented. ${ }^{44}$ There are four games, one for each appropriability environment. The payoffs are based on profit rankings as presented in tables 5 and 6. Table 7 indicates those TOC which form Nash equilibria in each game (each row represents a game). Only pure strategies are considered. In order to compare firms' preferences to social preferences, table 8 presents the ranking of welfare levels.

In the two games with $(1,1)$ and $(1,0)$, all TOC form Nash equilibria. Although optimal TOC could arise in a decentralised manner, there is no guarantee that they will. With no spillovers, the only Nash equilibrium is the $N C E$. As table 8 shows, in this case $W^{V C}>W^{N C}$ : the optimal TOC cannot be decentralized. Finally, with vertical spillovers all $T O C$ constitute Nash equilibria, except the $G C$. It happens that, as table 8 shows, this is the optimal TOC in this case.

Table 7- Nash equilibria

\begin{tabular}{|l|cccc|}
\hline & $\begin{array}{c}\text { No } \\
\text { cooperation }\end{array}$ & $\begin{array}{c}\text { Generalized } \\
\text { cooperation }\end{array}$ & $\begin{array}{c}\text { Horizontal } \\
\text { cooperation }\end{array}$ & $\begin{array}{c}\text { Vertical } \\
\text { cooperation }\end{array}$ \\
\hline No spillovers $(0,0)$ & $*$ & & $*$ & $*$ \\
\hline $\begin{array}{l}\text { Perfect horizontal spillovers } \\
\text { No vertical spillovers }(1,0)\end{array}$ & $*$ & $*$ & $*$ & $*$ \\
\hline $\begin{array}{l}\text { Perfect vertical spillovers } \\
\text { No horizontal spillovers }(0,1)\end{array}$ & $*$ & & & $*$ \\
Perfect spillovers $(1,1)$ & $*$ & $*$ & $*$ & $*$ \\
\hline
\end{tabular}

* An asterisk indicates a Nash equilibrium

\footnotetext{
${ }^{44}$ A complete stability analysis would require the study of the incentives of each firm and each possible coalition of firms to deviate, in each situation. Given that there are four strategies (TOC), four games (appropriability environments), and two types of firms, this would be exhaustive. Instead, stability is studied at the industry level: firms within a given industry always play the same strategy. Moreover, in principle, it would be possible to have asymmetric strategies. For instance, one industry could choose horizontal cooperation whereas firms in the other industry prefer not to cooperate among themselves. However, the payoffs presented in tables 5 and 6 are based on symmetric choices of cooperation, and this case is therefore not considered.
} 
Table 8- Ranking of welfare levels (based on numerical simulations) $(m=n=2)$

\begin{tabular}{|l|ccccc|}
\hline & $\begin{array}{c}\text { No } \\
\text { cooperation }\end{array}$ & $\begin{array}{c}\text { Generalized } \\
\text { cooperation }\end{array}$ & $\begin{array}{c}\text { Horizontal } \\
\text { cooperation }\end{array}$ & $\begin{array}{c}\text { Vertical } \\
\text { cooperation }\end{array}$ & $\begin{array}{c}\text { Social } \\
\text { optimum }\end{array}$ \\
\hline No spillovers $(0,0)$ & 3 & 4 & 5 & 1 & 1 \\
\hline $\begin{array}{l}\text { Perfect horizontal spillovers } \\
\text { No vertical spillovers }(1,0)\end{array}$ & 5 & 2 & 4 & 3 & 1 \\
\hline $\begin{array}{l}\text { Perfect vertical spillovers } \\
\text { No horizontal spillovers }(0,1)\end{array}$ & 4 & 2 & 5 & 3 & 1 \\
Perfect spillovers $(1,1)$ & 5 & 2 & 4 & 3 & 1 \\
\hline
\end{tabular}

Many observations can be made based on the preceding strategic interaction analysis. First, multiple equilibria arise in all appropriability environments, except when there are no spillovers. Second, the $N C E$ is always an equilibrium, even when there exist other equilibria which are more profitable to both buyers and sellers. By comparing the results of table 7 with those of table 8 (welfare ranking), we see that the decentralized equilibria may diverge largely from those $T O C$ which are socially desirable. Firms are often caught in a prisoner's dilemma situation. Third, the divergence between sellers' and buyers' interests shows the importance of the bargaining process in R\&D cooperation. Any form of asymmetry between firms can induce them to have different preferences with respect to cooperative settings. This negotiation dimension is often neglected in the theoretical study of R\&D agreements.

Early studies of strategic R\&D concluded from the social benefits of cooperation that R\&D support by the government is desirable. Later, some authors argued that because cooperation is also privately beneficial to firms, public intervention is not necessary. ${ }^{45}$ In the stability analysis it was shown how the profitability of some cooperative settings was not sufficient for them to arise as a result of decentralized negotiations. Conversely, cooperation settings benefiting firms do not always benefit society. Our analysis shows that the outcome of negotiation between asymmetric firms may result in something that is both socially and privately inferior. Government intervention on this dimension will be justified when private incentives (of both parties, or of the party capable of imposing its preferred TOC) diverge from the second-best alternative.

Table 7 shows that with no spillovers firms have no incentives to cooperate. Hence, not only does a strict patent policy reduce the diffusion of the innovation, but it also makes cooperative R\&D less attractive to firms. The model is consistent with the high rate of R\&D cooperation in Japan, since it predicts an inverse relation between appropriability and R\&D cooperation. ${ }^{46} 47$

\footnotetext{
${ }^{45}$ For instance, Steurs assumes that convergence between profitability and welfare is sufficient: "the type of cooperative agreement which is preferred by the firms because it results in the highest profitability, typically also results in the highest total welfare." (Steurs 1994:88). In the same spirit, Leahy and Neary (1997) argue that increased profitability to all firms from cooperation is sufficient to induce cooperation.

${ }^{46}$ As Baumol notes: "with little protection available from the patent system, Japanese innovators appear to have been driven to create profitable technology-sharing agreements with competitors and others" (1997:19).

${ }^{47} \mathrm{~A}$ drawback to this analysis of the incentives for cooperation is its overlooking of the high transaction costs of R\&D cooperation. $R \& D$ production, $R \& D$ cooperation and, more generally, knowledge, are characterised by high transaction costs. These are the costs of building and maintaining multi-firm cooperation, of leakage of information about technology and about strategies behind the technology, and of monitoring opportunistic behaviour (Fransman, 1990). For a discussion of the high transaction costs
} 


\section{Conclusions}

This paper focussed on vertical interindustry spillovers and vertical R\&D cooperation between firms. Whereas horizontal spillovers may increase or decrease innovation and welfare depending on prevailing cooperation types, vertical spillovers always increase them. Cooperative settings were compared in terms of R\&D. It was shown that no type of cooperation uniformly dominates the others. The type of cooperation yielding more R\&D depends on horizontal spillovers, vertical spillovers, and market structure. The ranking of cooperative structures hinges on the signs and magnitudes of three competitive externalities (vertical, horizontal, and diagonal) which capture the effect of the R\&D of a firm on the profits of other firms. The type of cooperation inducing firms to internalize a larger positive sum of competitive externalities yields more R\&D. In particular, one of the basic results of the strategic investment literature is that cooperation between competitors increases (decreases) $R \& D$ when horizontal spillovers are high (low); the model showed that this result does not necessarily hold when vertical spillovers and vertical cooperation are taken into account.

A theory of innovation and market structure was proposed: it was shown that the effect of competition in one industry on total innovation depends on horizontal spillovers, vertical spillovers, cooperative settings, and competition in the other industry. The relation between competition and innovation can be understood in terms of the horizontal, vertical, and diagonal competitive externalities. When the horizontal competitive externality dominates, the effect of competition on innovation is of the same sign as that externality if it is internalized, and of the opposite sign if it is not internalized. When the vertical competitive externality dominates, the effect of competition is always positive. When the diagonal competitive externality dominates (and that it is internalized), it is generally the Asymmetric model that prevails.

Finally, the analysis of the private incentives for cooperation showed that buyers and sellers have different preferences over cooperative settings: sellers prefer vertical cooperation, whereas buyers (generally) prefer horizontal cooperation. Higher spillovers increase the likelihood of cooperation, but the multiplicity of equilibria makes the decentralized choice of socially optimal cooperative settings uncertain.

An important question that arises in the study of vertical vs. horizontal cooperation and spillovers is their relative importance for firms' innovation and production decisions. The model suggests that horizontal spillovers have more impact on firms' decisions than vertical spillovers. A corollary is that horizontal cooperation, which internalizes those horizontal externalities, has more impact than vertical cooperation. For instance, when both types of spillovers are present, the effects of horizontal spillovers tend to dominate those of vertical spillovers. Also, in general, a change in the level of vertical spillovers affects the results quantitatively, while a change in the level of horizontal spillovers can affect the results both qualitatively and quantitatively. Moreover, vertical cooperation is (almost) always beneficial, but it increases $\mathrm{R} \& \mathrm{D}$ only marginally relative to the non-cooperative equilibrium; whereas horizontal cooperation can increase or decrease $\mathrm{R} \& \mathrm{D}$, but always significantly relative to the non-cooperative

associated with knowledge and R\&D, see Lee (1994). Moreover, different types of cooperation may have different transaction costs (I thank Michel Patry for this insight): one would expect that the hazards of horizontal cooperation are more important than the hazards of vertical cooperation. 
equilibrium. These observations are (generally) verified in figure 4 (comparison of types of cooperation), table 4 (market structure effects), tables 5 and 6 (buyers' and sellers' profits), and table 8 (Nash equilibria). This difference can be explained by the fact that the vertical competitive externality, even when it is not internalized, benefits the innovating firm because of the reduction in the total production cost of the final product. In contrast, the horizontal competitive externality does not always benefit the innovating firm: this depends on its sign, and its internalisation.

The identification of different types of interindustry spillovers is important for the empirical study of technology flows. Empirical studies have typically classified R\&D spillovers into two types: interindustry and intraindustry spillovers. The contrast of some of our results with Steurs $(1994,1995)$ -who studies spillovers between demand unrelated industries- shows the necessity to distinguish between spillovers between vertically related industries and those between demand unrelated industries, in addition to the classical distinction of intraindustry/interindustry spillovers.

The study of R\&D cooperation and of the protection of innovation inevitably raises important science and technology policy issues. Carefulness is required in drawing policy recommendations from this model because it abstracts from many real world issues, especially asymmetric information between policymakers and firms. Nonetheless the model provides some reflections on R\&D policy from the point of view of the incentives for cooperation, mergers, and vertical integration.

The model argues for a customized policy toward R\&D, as opposed to across the board standardized $R \& D$ policies. The optimal $R \& D$ policy varies according to horizontal spillovers, vertical spillovers, and the prevailing type of R\&D cooperation. Levin et al. (1987:816) reached a similar conclusion when they noted that "the incremental effects of policy changes should be assessed at the industry level". They further note that the impact of innovation protection depends on the extent of other appropriability mechanisms, which are industry specific.

Beyond traditional R\&D policy tools, the model suggests that the choice of cooperative settings and of incentives to cooperation, taking appropriability into account, is crucial for the determination of R\&D levels and distribution. This approach should be seen as a complement, rather than as a substitute, to traditional policy leverages.

The model predicts that spillovers increase the gains -to firms and to society- from cooperation, so it can be argued that higher spillovers should induce more R\&D incentives. However, spillovers also increase the likelihood that firms will cooperate: when spillovers are high, many or all TOC constitute Nash equilibria, and one could hence argue that firms would cooperate because it is profitable for them to do so. On the other hand, with multiple equilibria, there is no guarantee that firms will choose cooperation over no cooperation, or that they will choose the socially optimal type of cooperation.

The interpretation of the choice of $T O C$ should be broader than the special cooperative settings studied here. In the model different combinations of vertical and horizontal cooperation were considered. However, cooperation has many other dimensions. The same basic problem arising here with respect to the choice of the -privately or socially- preferred types of cooperation is expected to arise, at a much larger scale, when all the richness of cooperative settings is considered: choice of research projects, extent of cooperation, information sharing, enforcement mechanisms, intellectual property rights, etc. This gives the government a larger scope for intervention. 
The model emphasized the vertical dimension of innovation, in terms of vertical R\&D spillovers and vertical R\&D cooperation. Geroski (1992) has made a clear call for more focus on the role of vertical relations, and perhaps less on horizontal relations, which can lead to collusion on the output market. Vertical cooperation does not bring with it all the potentially anti-competitive effects of horizontal research joint ventures. ${ }^{48}$ Moreover, vertical cooperation may require less incentives than horizontal cooperation, for it is easier to induce firms into cooperating with suppliers/distributors than into cooperating with competitors.

The results have implications for merger analysis. Mergers usually entail the use of R\&D -in addition to output- to maximize joint profits. Economists have tended to focus on the output effects of mergers; more attention needs to be drawn to the innovation effects of mergers. The results show that the innovation effects of horizontal mergers, apart from any output distortions, depend on the level of horizontal spillovers. Depending on the appropriability conditions and the type of R\&D cooperation prevailing before the merger, the merger may reinforce or mitigate the negative effect of output reduction by increases or reductions in innovation. For instance, regulators should be severe regarding mergers where output decisions are joint but where $R \& D$ decisions remain separate. The innovation effects of vertical mergers also need to be considered: vertical integration makes vertical $R \& D$ cooperation intrinsic to the structure of the firm, thus increasing R\&D.

The model has many possible extensions. An important type of vertical cooperation that has not been addressed by the paper is vertical cooperation when the upstream sector is the developer of the innovation and the downstream sector is the user of the innovation. It was assumed that upstream and downstream firms conducted the same type of research. In real markets, downstream firms are closer to the final user, and may be engaged in more applied research, whereas upstream levels may be conducting more fundamental research. Insofar as appropriability problems are thought to be more severe in basic research than in applied research (Arrow, 1962), spillovers between suppliers may be higher than spillovers between buyers. This in turn may affect the symmetry of vertical spillovers assumed in this paper. Finally, when the levels of concentration in the upstream and downstream industries are very different, vertical cooperation takes place between firms of different sizes, and therefore of different technological, financial, and managerial capabilities. ${ }^{49}$

\footnotetext{
${ }^{48}$ Examples are production of a technology of the lower common denominator (Dodgson, 1994), reduction in the diversification of research paths, barriers to entry, elimination of competitors, output collusion, and collusion to control the technological cycle.

${ }^{49}$ This is the case, for instance, within SEMATECH (the Semiconductor Manufacturing Technology Consortium), where large semiconductor firms cooperate with small semiconductor materials and equipment suppliers.
} 


\section{Figure 1}

\section{Types of cooperation (TOC)}

\begin{tabular}{|c|c|c|c|}
\hline \multirow{2}{*}{ No cooperation } & Seller 1 & $\ldots$ & Seller $n$ \\
\hline & Buyer 1 & $\ldots$ & Buyer m \\
\hline \multirow{2}{*}{$\begin{array}{l}\text { Generalized } \\
\text { cooperation }\end{array}$} & Seller 1 & $\ldots$ & Seller $\mathrm{n}$ \\
\hline & Buyer 1 & $\ldots$ & Buyer m \\
\hline \multirow{2}{*}{$\begin{array}{l}\text { Horizontal } \\
\text { cooperation }\end{array}$} & \begin{tabular}{|l|} 
Seller 1 \\
\end{tabular} & $\ldots$ & Seller $\mathrm{n}$ \\
\hline & Buyer 1 & $\ldots$ & Buyer $\mathrm{m}$ \\
\hline \multirow{2}{*}{$\begin{array}{l}\text { Vertical } \\
\text { cooperation* }\end{array}$} & Seller 1 & & Seller $n$ \\
\hline & Buyer 1 & & Buyer m \\
\hline
\end{tabular}

A block represents a group of cooperating firms

* With vertical cooperation, where each buyer cooperates with one seller, symmetric strategies require imposing the restriction $\mathrm{m}=\mathrm{n}$. 


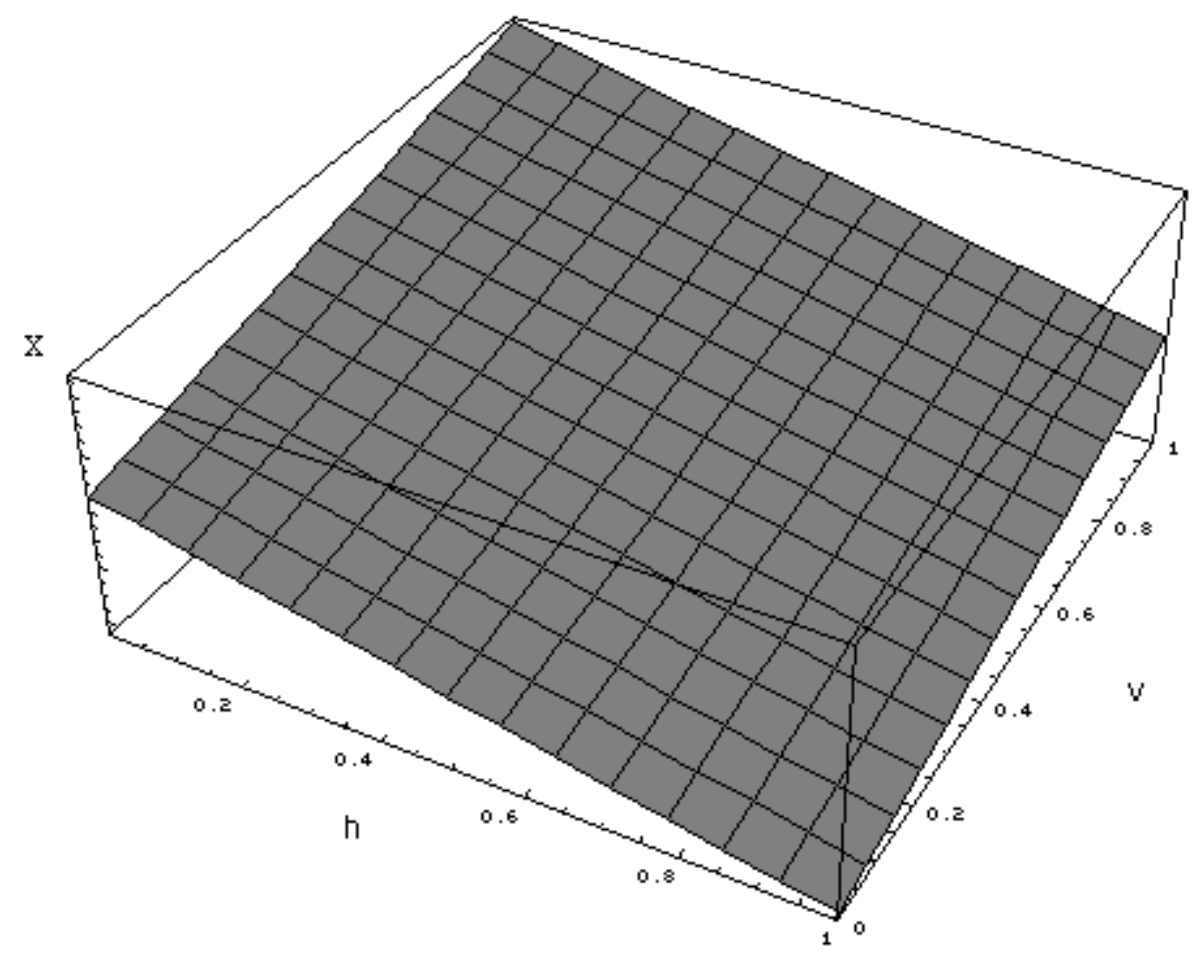

Figure 2

Effects of spillovers on R\&D

$2 \mathrm{a}$

No cooperation

and

Vertical cooperation

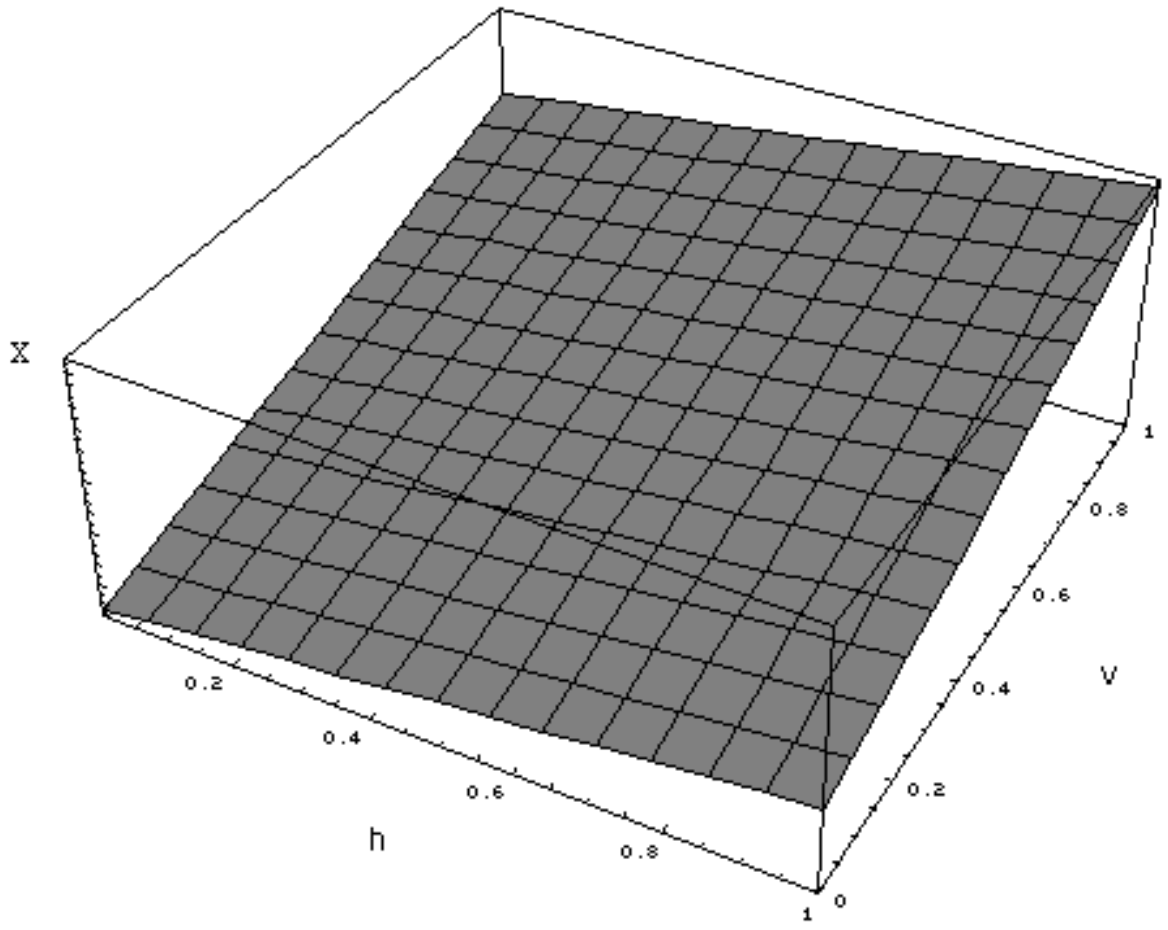

$2 \mathrm{~b}$

Horizontal Cooperation and

Generalized Cooperation 
Figure 3

Effect of cooperation on R\&D [ $m=n=2$ ]

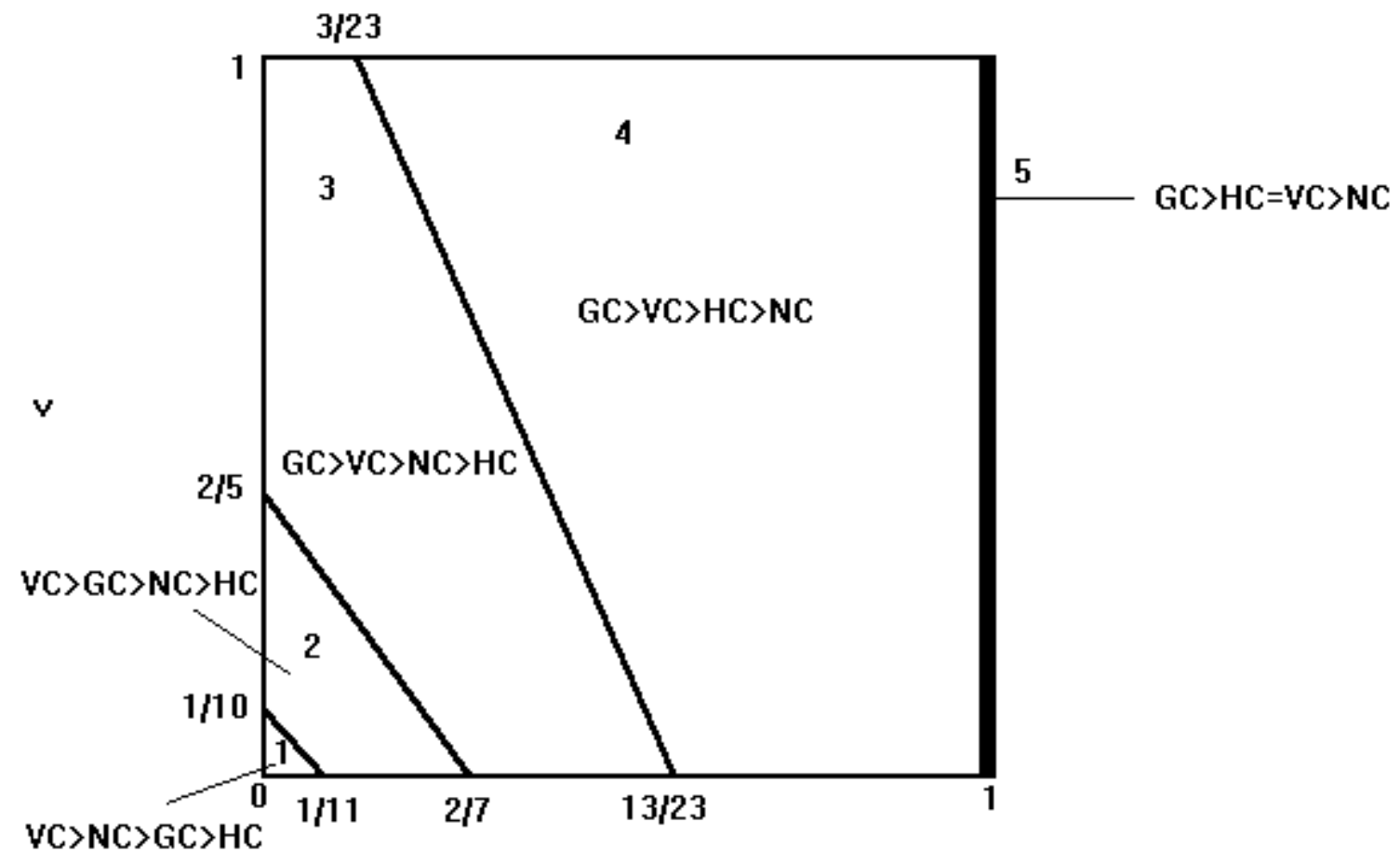



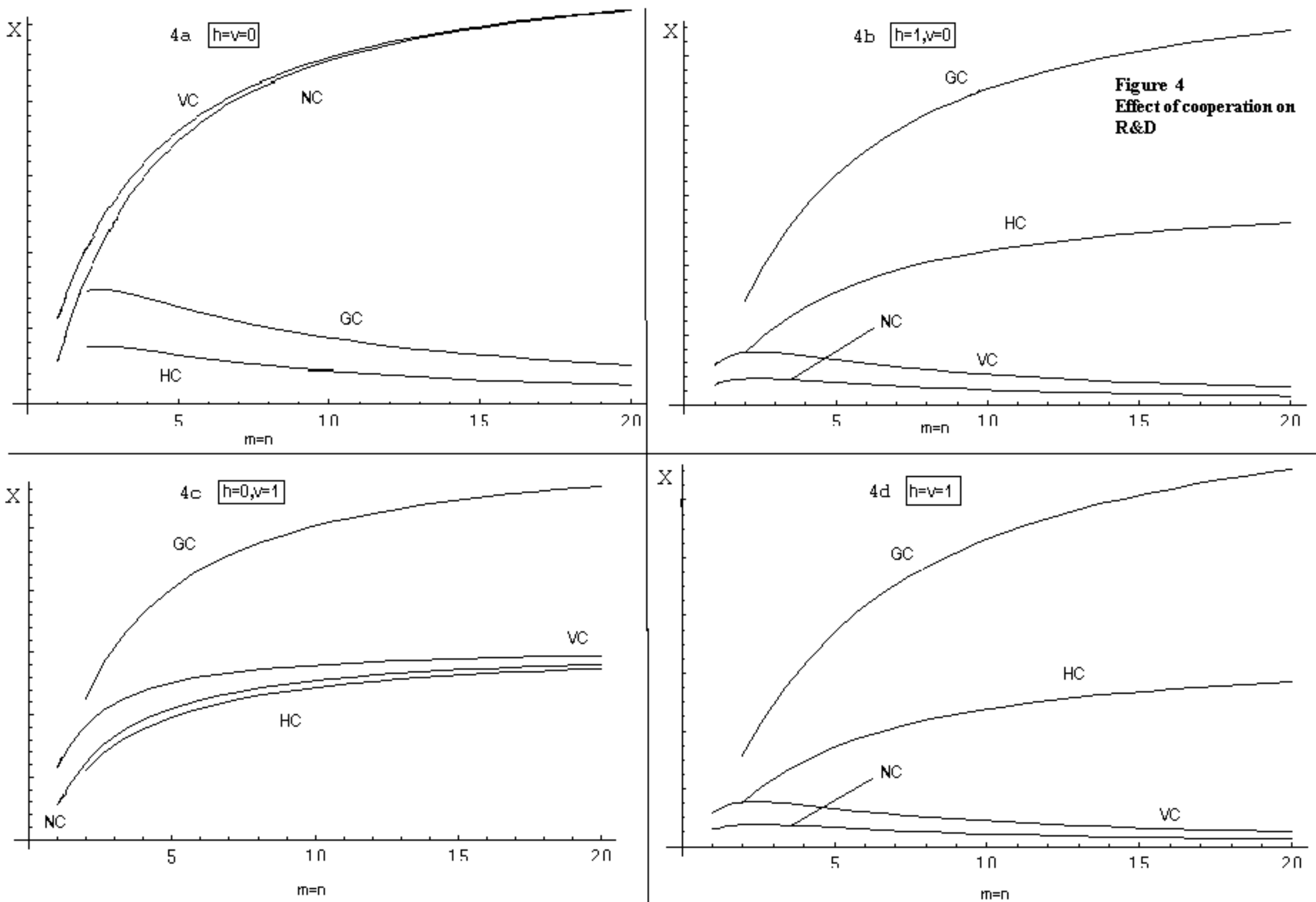
5 a

The Competitive model

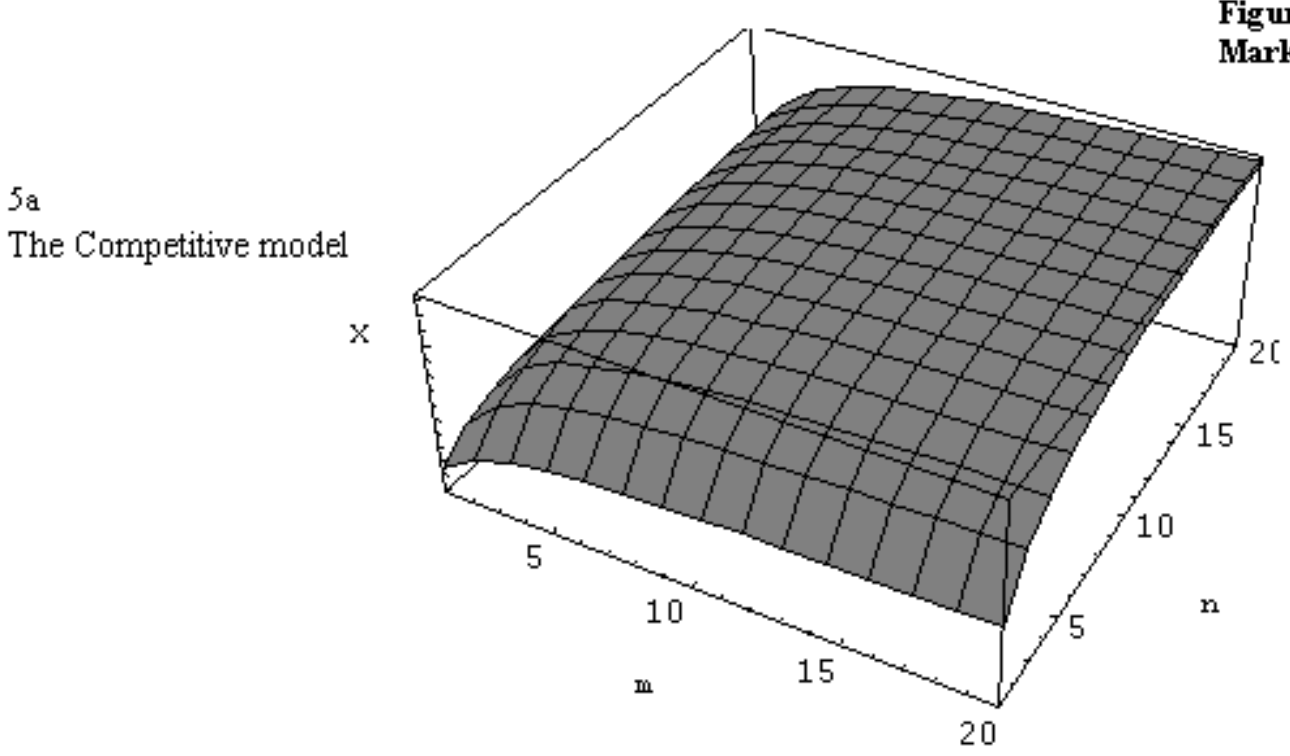

Figure 5

rket Structure and Innovation

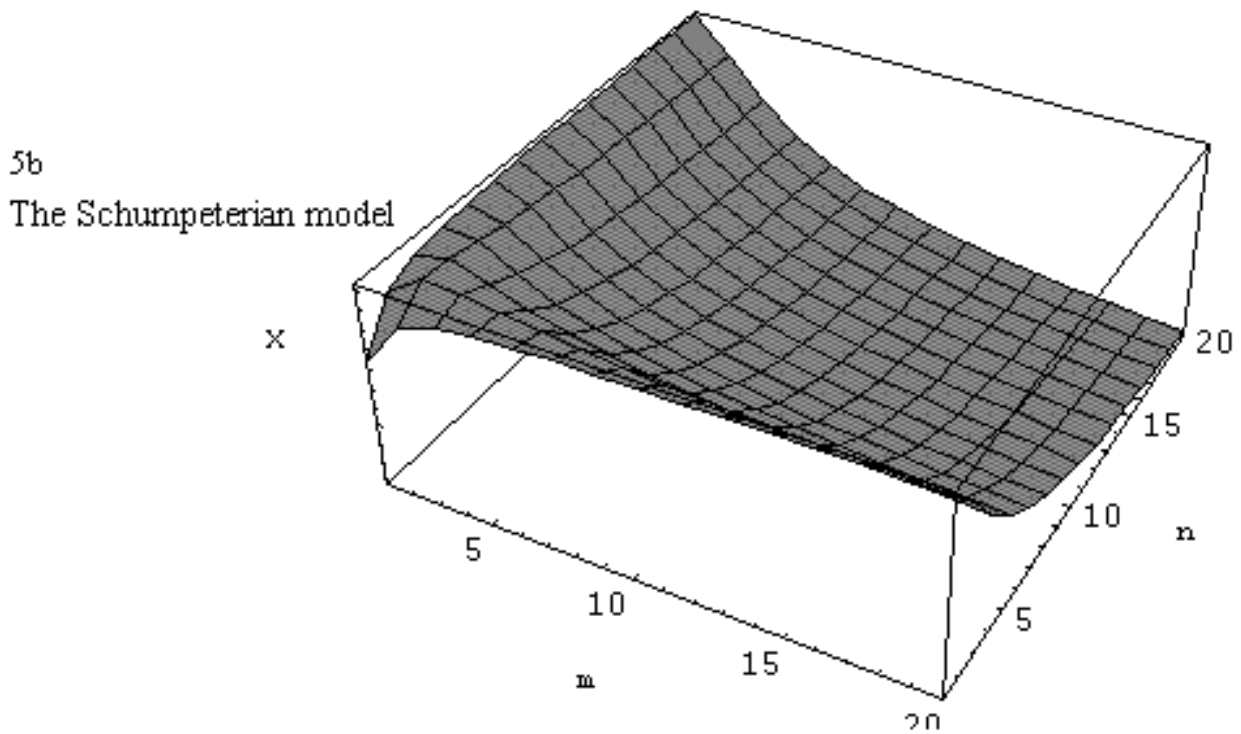

$5 c$

The Asymmetric model

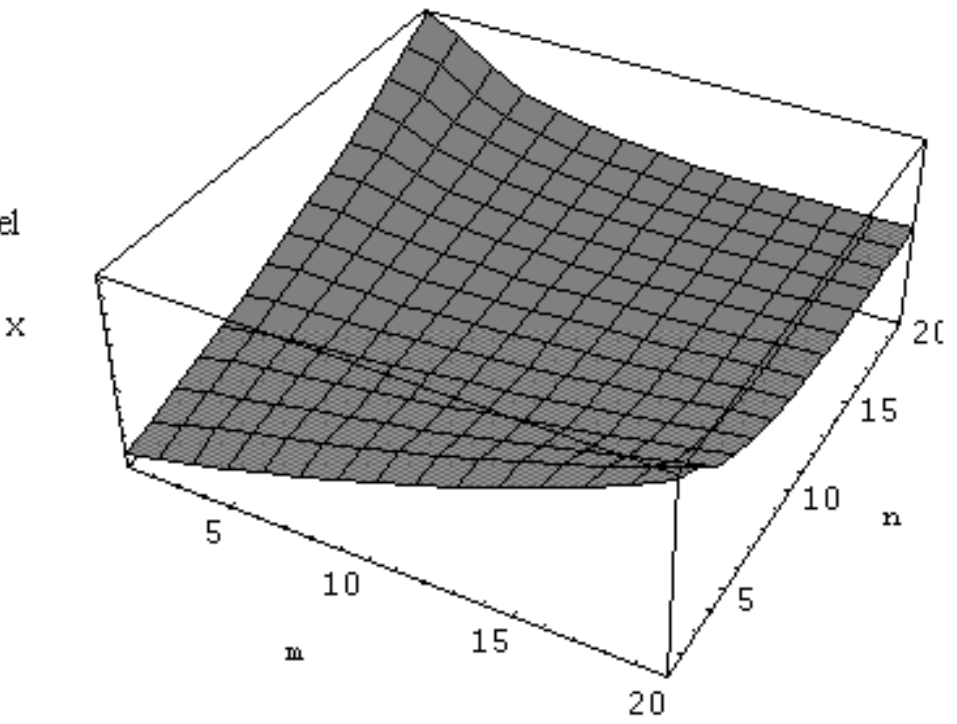




\section{Bibliography}

Aghion, P., and Tirole, J., 1993, On the Management of Innovation, Working Paper 93-12, Department of Economics, MIT.

Alston, J.M., and Scobie, G.M., 1983, 'Distribution of Research Gains in Multistage Production Systems: Comment', American Journal of Agricultural Economics, 353-56.

Arrow, K.J., 1962, 'Economic Welfare and the Allocation of Resources for Invention', in Nelson, R. (ed.), The Rate and Direction of Inventive Activity, Princeton University Press.

Baumol W.J., 1997, Pareto Optimal Sizes of Innovation Spillovers, Research Report \# 97-42, The C.V. Starr Center for Applied Economics, Department of Economics, New York University.

Becker, W., and Peters, J., 1995, R\&D-Competition between Vertical Corporate Networks: Structure, Efficiency and R\&D-Spillovers, Working Paper No. 144, Institut für Volkswirtschaftslehre, Universität Augsburg.

Bernstein, J.I., 1988, 'Costs of Production, Intraindustry and Interindustry R\&D Spillovers: Canadian Evidence', Canadian Journal of Economics, 21(2):324-47.

Bernstein, J.I., and Nadiri, M.I., 1988, 'Interindustry R\&D Spillovers, Rate of Return, and Production in High-technology Industries', AER, 78(2):429-34.

Bester, H., and Petrakis, E., 1993, 'The incentives for cost reduction in a differentiated industry', International Journal of Industrial Organization, 11:519-34.

Boivin, C., and Vencatachellum, D., 1998, 'Externalités et coopération en recherche et développement: une reconceptualisation', L'Actualité Économique, 74(4):633-49.

Branstetter, L., 199?, "Production keiretsu and knowledge transfers in Japanese manufacturing firms", Financial Review, Vol. 46.

Cassiman, B., and Veugelers, R., 1998, R\&D Cooperation and Spillovers: Some Empirical Evidence, Working paper, Universitat Pompeu Fabra/Katholieke Universiteit Leuven.

Choe, C., 1998, Two Comments On the Industrial Organisation of Vertically Related Markets, Discussion Paper No. A98.03, School of Business, La Trobe University.

Clark, K., Chew, W., and Fujimoto, T., 1987, 'Product development in the world auto industry', Brookings Papers on Economic Activity, 3:729-81.

Cohen, W.M., and Levinthal D.A., 1990, 'The implications of spillovers for R\&D investment and welfare: a new perspective', in Link, A.N., and Smith, V.K., Advances in Applied MicroEconomics: A Research Annual, Vol. 5.

d'Aspremont, C., and Jacquemin, A., 1988, 'Cooperative and Noncooperative R\&D in Duopoly with Spillovers', AER, 78:1133-37.

Dasgupta, P., and Stiglitz, J., 1980, 'Industrial Structure and the Nature of Innovative Activity', Economic Journal, 90(358):266-93.

De Bondt, R., 1996, 'Spillovers and innovative activities', International Journal of Industrial Organization, 15:1-28.

De Bondt, R., Wu, C., and Lievens, D., 1992, Stable Strategic R\&D Cartels, Onderzoeksrapport NR. 9204, Departement Toegepaste Economische Wetenschappen, Katholieke Universiteit Leuven.

De Bondt, R., and Wu, C., 1997, 'Research Joint Venture Cartels and Welfare', in Poyago-Theotoky, J. (ed.), Competition, Cooperation, Research and Development: The Economics of Research Joint Ventures, Macmillan Press Ltd, London.

Delbono, F., and Denicolo, V., 1990, 'R\&D investment in a symmetric and homogeneous oligopoly: Bertrand vs. Cournot', International Journal of Industrial Organization, 8:297-314.

Dodgson, M., 1994, 'Technological Collaboration and Innovation', in Dodgson, M., and Rothwell, R. 
(eds.), The Handbook of Industrial Innovation, Elgar, Aldershot, U.K.

Dyer, J.H., and Ouchi, W.G., 1993, 'Japanese-Style Partnerships: Giving Companies a Competitive Edge', Sloan Management Review, Fall, 51-63.

Eaton, B.C., and Eswaran, M., 1997, 'Technology-trading coalitions in supergames', RAND Journal of Economics, 28(1):135-49.

Fransman, M., 1990, The market and beyond: Cooperation and competition in information technology development in the Japanese System, Cambridge University Press, Cambridge.

Freebairn, J.W., Davis, J.S., and Edwards, G.W., 1982, 'Distribution of Research Gains in Multistage Production Systems', American Journal of Agricultural Economics, 39-46.

Geroski, P.A., 1992, 'Vertical Relations between Firms and Industrial Policy', Economic Journal, 102(410):138-47.

Goel, R.K., 1990, 'Innovation, Market Structure, and Welfare: A Stackelberg Model', Quarterly Review of Economics and Business, 30(1):40-53.

Goto, A., and Suzuki, K., 1989, 'R\&D Capital, Rate of Return on R\&D Investment and Spillover of R\&D in Japanese Manufacturing Industries', The Review of Economics and Statistics, 71(4):55564.

Greenhut, M.L., and Ohta, H., 1979, 'Vertical Integration of Successive Oligopolists', AER, 69(1):26777.

Grindley, P., Mowery, D., and Silverman, B., 1994, 'SEMATECH and collaborative research: lessons for the Design of High Technology Consortia', Journal of policy analysis and management, 35:723-58.

Hagedoorn, J., Link, A.N., and Vonortas, N.S., 2000, 'Research partnerships’, Research Policy, 29:56786.

Harhoff, D., 1991, R\&D Incentives and Spillovers in a Two-Industry Model, Zentrum für Europäische Wirtschaftsforschung $\mathrm{GmbH}$, Industrial Economics and International Management Series, Discussion Paper No. 91-06.

Henriques, I., 1991, The Optimal Novelty Requirement in a Duopolistic Setting - a two-stage analysis of an R\&D-model with spillovers, Working Paper, York University.

Irmen, A., 1997, 'Mark-up pricing and bilateral monopoly', Economics Letters, 54:179-84.

Jaffe, A.B., 1986, 'Technological Opportunity and Spillovers of R\&D: Evidence from Firms' Patents, Profits, and Market Value', AER, 79(5):957-70.

Jarmin, R.S., 1993, ‘Asymmetric Learning Spillovers', Economic Studies, 93-7.

Jorde, T.M., and Teece, D.J., 1990, 'Innovation and Cooperation: Implications for Competition and Antitrust', Journal Of Economic Perspectives, 4(3):75-96.

Jorde, T.M., and Teece, D.J., 1992, 'Innovation, Cooperation, and Antitrust', in Jorde, T.M., and Teece, D.J., Antitrust, Innovation, and Competitiveness, Oxford University Press, N.Y.

Kamien, M.I., and Schwartz, N.L., 1982, Market Structure and Innovation, Cambridge University Press, Cambridge, N.Y.

Kamien, M.I., Muller, E., and Zang, I., 1992, 'Research Joint Ventures and R\&D Cartels', AER, 82(5):1293-1306.

Kamien, M.I., and Zang, I., 1993, 'Competing Research Joint Ventures', Journal of Economics and Management Strategy, 2(1):23-40.

Kesteloot, K., and Veugelers, R., 1995, 'Stable R\&D Cooperation with Spillovers', Journal of Economics \& Management Strategy, 4(4):651-72.

Leahy, D., and Neary, J.P., 1997, 'Public Policy Towards R\&D in Oligopolistic Industries', AER, 87(4):642-62. 
Lee, Y.H., 1994, Vertical Integration and Technological Innovation: a Transaction Cost Approach, Garland Publishing Inc., N.Y.

Levin, R.C., Klevorick, A.K., Nelson, R.R., and Winter, S.G., 1987, 'Appropriating the Returns from Industrial Research and Development', Brookings Papers on Economic Activity, pp.783-820.

Levin, R.C., and Reiss, P.C., 1988, 'Cost-reducing and demand-creating R\&D with spillovers', RAND Journal of Economics, 19(4):538-56.

Mansfield, E., 1985, 'How rapidly does new industrial technology leak out', Journal of Industrial Economics, 34:217-23.

Mohnen, P., 1989, New Technologies and Inter-industry Spillovers, Working Paper, CERPE, Université du Québec à Montréal.

Nadiri, M.I., 1993, Innovations and Technological Spillovers, Working Paper No. 4423, NBER.

Pavitt, K., 1984, 'Sectoral Patterns of Technical Change: Towards a Taxonomy and Theory', Research Policy, 13:343-73.

Peters, J., 1995, Inter-Industry R\&D-Spillovers between Vertically Related Industries: Incentives, Strategic Aspects and Consequences, Working Paper No. 139, Institut für Volkswirtschaftslehre, Universiät Augsburg.

Peters, J., 2000, 'Buyer Market Power and Innovative Activities: Evidence for the German Automobile Industry', Review of Industrial Organisation, 16:13-38.

Poyago-Theotoky, J., 1995, 'Equilibrium and optimal size of a research joint venture in an oligopoly with spillovers', Journal of Industrial Economics, 43:209-25.

Poyago-Theotoky, J., 1996, 'R\&D Competition with Asymmetric Firms', Scottish Journal of Political Economy, 43(3):334-42.

Rosen, R.J., 1991, 'Research and development with asymmetric firm sizes', The RAND Journal of Economics, 22(3):411-29.

Ruff, L.E., 1969, 'Research and technological progress in a Cournot economy', Journal of Economic Theory, 1:397-415.

Sako, M., 1995, Suppliers' Associations in the Japanese Automobile Industry: Collective Action for Technology Diffusion, Discussion Paper No.1147, Centre for Economic Policy Research, London.

Salant, S.W., and Shaffer, G., 1998, 'Optimal Asymmetric Strategies in Research Joint Ventures', International Journal of Industrial Organization, 16(2):195-208.

Spence, M., 1984, 'Cost reduction, competition and industry performance', Econometrica, 52:101-21.

Steurs, G., 1994, Spillovers and Cooperation in Research and Development, Ph.D. Thesis, Katholieke Universiteit Leuven.

Steurs, G., 1995, 'Inter-industry R\&D spillovers: What difference do they make', International Journal of Industrial Organization, 13:249-76.

Suzuki, K., 1993, 'R\&D spillovers and technology transfer among and within vertical keiretsu groups', International Journal of Industrial Organization, 11(4):573-91.

Suzumura, K., 1990, Cooperative and Noncooperative R\&D in Oligopoly with Spillovers, Working Paper, Hitosubashi University.

Suzumura, K., 1992, 'Cooperative and Noncooperative R\&D in Oligopoly with Spillovers', AER, 82(5):1307-20.

Teece, D.J., 1992, 'Competition, cooperation, and innovation: Organizational arrangements for regimes of rapid technological progress', Journal of Economic Behavior and Organization, 18:1-25.

Terleckyj, N.E., 1974, Effects of R\&D on the Productivity Growth of Industries: An Exploratory Study, National Planning Association, Washington, D.C. 
Tirole, J., 1989, The Theory of Industrial Organization, The MIT Press, Cambridge, Massachusetts. VanderWerf, P.A., 1992, 'Explaining downstream innovation by commodity suppliers with expected innovation benefit', Research Policy, 21:315-33.

Veugelers, R., 1993, A Profile of Companies in Alliances, Working Paper, K.U. Leuven.

Von Hippel, E., 1988, The Sources of Innovation, MIT Press, Cambridge.

Ward, M.R., and Dranove, D., 1995, 'The vertical chain of research and development in the pharmaceutical industry', Economic Inquiry, 33(1):70-87.

Wolff, E.N., and Nadiri, M.I., 1993, 'Spillover Effects, Linkage Structure, and Research and Development', Structural Change and Economic Dynamics, 4(2):315-31.

Yi, S.S., 1998, Endogenous formation of joint ventures with efficiency gains, Working paper, Dartmouth College.

Young, A.R., 1991, 'Vertical structure and Nash equilibrium: a note', The Journal of Industrial Economics, 39(6):717-22. 


\section{Liste des publications au CIRANO *}

\section{Cahiers CIRANO / CIRANO Papers (ISSN 1198-8169)}

99c-1 Les Expos, l'OSM, les universités, les hôpitaux : Le coût d'un déficit de 400000 emplois au Québec — Expos, Montréal Symphony Orchestra, Universities, Hospitals: The Cost of a 400,000-Job Shortfall in Québec / Marcel Boyer

96c-1 Peut-on créer des emplois en réglementant le temps de travail? / Robert Lacroix

95c-2 Anomalies de marché et sélection des titres au Canada / Richard Guay, Jean-François L'Her et Jean-Marc Suret

95c-1 La réglementation incitative / Marcel Boyer

94c-3 L'importance relative des gouvernements: causes, conséquences et organisations alternative / Claude Montmarquette

94c-2 Commercial Bankruptcy and Financial Reorganization in Canada / Jocelyn Martel

94c-1 Faire ou faire faire : La perspective de l'économie des organisations / Michel Patry

Série Scientifique / Scientific Series (ISSN 1198-8177)

2000s-53 Information Sharing and the Stability of Cooperation in Research Joint Ventures / Gamal Atallah

2000s-52 A Theory of Routines as Mindsavers / Bernard Sinclair-Desgagné et Antoine Soubeyran

2000s-51 Can Financial Intermediation Induce Economic Fluctuations? / Sanjay Banerji et Ngo Van Long

2000s-50 Information Technology Sophistication in Hospitals: A Field Study in Quebec / Guy Paré et Claude Sicotte

2000s-49 Does Comparable Worth Work in a Decentralized Labor Market? / Michael Baker et Nicole M. Fortin

2000s-48 Occupational Gender Composition and Wages in Canada: 1987-1988 / Michael Baker et Nicole M. Fortin

2000s-47 Économétrie, théorie des tests et philosophie des sciences / Jean-Marie Dufour

2000s-46 Factor Analysis and Independent Component Analysis in Presence of High Idiosyncratic Risks / Thierry Vessereau

2000s-45 Aspects non linéaires du marché des actions français / Thierry Vessereau

2000s-44 Étude du modèle d'évaluation par arbitrage sur le marché des actions suisses / Thierry Vessereau

2000s-43 Habit Formation with Recursive Preferences / Aylin Seckin

2000s-42 Habit Formation: A Kind of Prudence? / Aylin Seckin

2000s-41 Consumption with Liquidity Constraints and Habit Formation / Aylin Seckin

2000s-40 Consumption-Leisure Choice with Habit Formation / Aylin Seckin

\footnotetext{
* Vous pouvez consulter la liste complète des publications du CIRANO et les publications elles-mêmes sur notre site Internet à l'adresse suivante :
}

http://www.cirano.umontreal.ca/publication/documents.html 